\title{
Electron Impact Ionisation and Fragmentation of Methanol and Ethanol
}

KL Nixon $^{1,2^{*}}$, WAD Pires ${ }^{1}$, RFC Neves $^{1,3}$, HV Duque $^{1}$, DB Jones ${ }^{4}$, MJ Brunger $^{4,5}$ and MCA Lopes ${ }^{1}$

${ }^{1}$ Departamento de Física, Universidade Federal de Juiz de Fora, Juiz de Fora, MG, 36936-900, Brazil

${ }^{2}$ School of Biology, Chemistry and Forensic Science, University of Wolverhampton, Wolverhampton WV1 1LY, UK

${ }^{3}$ Instituto Federal do Sul de Minas Gerais, Campus Pocços de Caldas, Minas Gerais, Brazil

${ }^{4}$ School of Chemical and Physical Sciences, Flinders University, GPO Box 2100, Adelaide SA 5001, Australia

${ }^{5}$ Institute of Mathematical Sciences, University of Malaya, 50603 Kuala Lumpur, Malaysia

* corresponding author: kate.nixon@wlv.ac.uk

\begin{abstract}
Electron impact ionisation and dissociative ionisation of the two smallest primary alcohols have been investigated. A quadrupole mass spectrometer was used, with an internal ionising electron source resulting in an energy resolution of $\sim 0.8 \mathrm{eV}$. The partial ionisation cross sections (PICS) for a number of individual cations have been measured for energies between $10-100 \mathrm{eV}$. The present data compares well with previous results for methanol. Surprisingly, however, this study is the first to report individual PICS for ethanol. The sum of the present PICS for both methanol and ethanol is also compared to the total ionisation cross sections reported in the literature and are found to be in good accord. Additionally, appearance energies have been derived by fitting the Wannier equation to data measured within $\sim 2 \mathrm{eV}$ of the cation formation threshold. However, the low energy resolution limits the precision with which these values are able to be determined. This study also establishes the validity of the data collected using the apparatus at Universidade Federal de Juiz de Fora (UFJF) and so provides a solid foundation for further studies of larger alcohols.
\end{abstract}


Keywords: Electron impact ionisation, partial ionisation cross sections, methanol, ethanol

\section{Introduction}

Addressing climate change is currently thought to be one of the most serious challenges for humanity [1]. One of the major contributors to global warming has been the increased emission of greenhouse gases to meet growing power consumption needs. Of these greenhouse gas emissions, $72 \%$ is $\mathrm{CO}_{2}$ released by the indiscriminate burning of fuels derived from petroleum and its derivatives in the household, industry and automotive transportation [2,3]. Therefore, finding alternative sources of energy not derived from petroleum is a strategy that is gaining increasing attention from government, non-governmental organizations and from academic institutions. Indeed, many countries have in place strategies with strict targets for reducing their carbon emissions [4]. These strategies usually revolved around reducing deforestation and moving towards sustainable energy resources. A key component of this is replacing fossil fuels, such as coal, natural gas and oil with renewable alternatives. The replacement of fossil fuels by bio-fuels within the automotive industry could have a large effect on reducing the emission of $\mathrm{CO}_{2}$, and also other toxic by-products such as mono-nitrogen species $\left(\mathrm{NO}_{\mathrm{x}}\right)$, volatile organic compounds and particulate matter. As bio-fuels are generally comprised of smaller molecules, they burn cleaner with fewer toxic species being emitted [5]. However, the combustion of these fuels needs to be better understood and optimised in order to realise the most efficient operating conditions of engines for complete combustion and highest energy release [6]. The plasma created with the ignition spark in the engines can be modelled theoretically, providing the optimum parameters to be used in cars. These models involve the knowledge of electron collision data for elastic collisions as well as excitation, ionisation, dissociation and electron attachment, with some of these cross sections being the subject of this work. Ideally, this information should be provided for all of the species present at the ignition of the plasma and also those species created by the plasma, such as the positive and negative ions, radicals and neutral fragments. For this reason there has been a number of experimental and theoretical electron scattering investigations from small alcohols (see below).

Methanol is the smallest alcohol and has therefore been the most studied as it can be considered as a prototype for larger alcohols. Experimental and theoretical investigations include total [7-14] and elastic differential cross sections [13,15-17], from which integral cross sections and momentum transfer cross sections can also be derived. Most recently, there has been a study of the electronic excitation of methanol by electron impact [18] which is important as the excited electronic states may provide a pathway to neutral dissociation. In terms of ionisation, experimental absolute total ionisation cross sections (TICS) have been reported [19-22], as well as corresponding results from theoretical studies [23-25]. To gain insights into the combustion process, the residual products in the 
exhaust are often analysed. An accurate knowledge of fragmentation pathways in dissociative ionization mass spectra is therefore essential. This has led to detailed investigations reporting partial ionisation cross sections for the formation of individual positive ions. Srivastava et al. [20] reported absolute experimental PICS for 10 individual cations from 20-500 eV using a QMS mass filter and a relative flow technique with helium as the reference gas, while Pal [24] used a semi-empirical approach to predict the PICS for 12 cations over a similar energy range of 12-500 eV. Rejoub et al. [21] presented absolute PICS, up to $1000 \mathrm{eV}$, for groups of cations with similar mass. The mass separation was achieved by two plates with a $3 \mathrm{kV}$ potential difference across them, separating ions of different mass based on their flight time. The apparatus of Rejoub et al. [21] sacrificed mass resolution for the ability to collect all of the ions, regardless of their kinetic energy. Absolute data were obtained based on a knowledge of the number of ions produced, the number of electrons, the cell dimensions and the number density of the target gas. Additionally, Douglas et al. [26] reported relative PICS over a smaller energy range of $30-200 \mathrm{eV}$, again using an apparatus employing a time of flight mass filter, this time based on a Wiley-McLaren design, and suggested that the vast majority of ions with kinetic energies less $9 \mathrm{eV}$ would be collected. In each case the PICS are presented relative to the parent ion. Hudson et al. [22] used a total ionisation cell to measure the absolute TICS of methanol and ethanol, with no mass selectivity. The absolute scale was determined in a similar fashion to that of Rejoub et al., namely by measurements of the pressure, temperature and the length of the cell. Zavilopulo et al. also give relative PICS, for energies less than $30 \mathrm{eV}$ [27], as well as reporting appearance energies (AEs). The apparatus employed to measure these values used an electron source with an energy resolution comparable to that of Srivastava et al. [20], $\sim 0.5 \mathrm{eV}$, and a monopole mass selector. Finally, Cummings and Bleakney [28] also reported the appearance energies for a selection of the cations, generated by electron impact ionization of methanol, using a $180^{\circ}$ mass selector which was typically utilised at the time of those measurements.

Considerably, less information is available for electron interactions with ethanol. Total $[7,11]$ and elastic differential, integral and momentum transfer cross sections $[13,16]$ have been measured, as have total ionisation cross sections $[19,21,22]$. Theoretical TICS have also been reported [22,23,25]. The only PICS available are those of Rejoub et al [21], who again report PICS for groups of cations of similar mass. In this respect, the PICS presented here represent the first measurements for individual cations created by electron impact ionisation from ethanol. The appearance energies of ethanol have been previously reported in the study of Cummings and Bleakney [28], for a subset of the possible cations.

In this study we present partial ionisation cross sections from methanol and ethanol by electron impact from $10-100 \mathrm{eV}$. This data provides a valuable addition to that available for modelling the plasma created during combustion of bio-fuels. A sum of the present methanol and ethanol PICS, measured for the majority of cations created, results in TICS which compare well to those within the literature. 
In addition, we have determined the appearance energies for a range of cations for both methanol and ethanol.

The remainder of this manuscript is organised as follows. The experimental details and analysis methods are described in section 2, while the mass spectra, ionisation cross sections and appearance energies are presented in section 3. The present data are compared, where possible, with those currently available in the literature and discussed in this section. Finally, some conclusions from this investigation are summarised in section 4 , which also outlines possible future directions at UFJF.

\section{Experimental Methods and Analysis}

The experimental data for electron impact ionisation of methanol and ethanol were collected using the commercial Hiden Analytical [29] Energy Pulse Ion Counting quadrupole mass spectrometer (QMS), fitted with an RF head capable of measuring masses up to 300 amu (EPIC 300). The EPIC 300 consists of an ion extractor, focusing lens, triple stage quadrupole mass filter and a secondary electron multiplier to amplify the signal generated by the detection of an ion. Additionally, the EPIC 300 also has an ionization stage and can be operated in a residual gas analysing (RGA) mode. Here the internal ionisation source, a yttria coated iridium filament, is used to create ions by electron impact ionisation. The QMS is fitted in a vacuum chamber $38 \mathrm{~cm}$ in diameter and $46.5 \mathrm{~cm}$ in length, evacuated by a $2000 \mathrm{l} / \mathrm{s}$ turbomolecular pump backed by a dry scroll pump, achieving a base pressure of $\sim 2 \times 10^{-7}$ torr. The target molecules effuse from a needle with an internal diameter of $1.0 \mathrm{~mm}$, which is positioned perpendicular to the axis of the mass filter and $30 \mathrm{~mm}$ below the entrance to the ionisation stage. Therefore the ions created in the ionisation stage of the QMS are most likely to arise from the uniform background of target molecules accumulated within the chamber when the needle value is open, rather than from molecules effusing directly from the needle.

Methanol and ethanol (Sigma Aldrich [30], assay 99.9\% and 95\%, respectively) samples were respectively purified by several freeze-pump-thaw cycles before the vapour was admitted into the chamber. The flow of the target molecules into the chamber was regulated by a needle valve (MLV22 [31]). The gas handling lines were heated to $\sim 40{ }^{\circ} \mathrm{C}$ to prevent condensation of the vapour along the lines and yield a stable operating pressure. The sample vessel did not require heating and remained at the temperature of the air-conditioned laboratory, i.e., $22{ }^{\circ} \mathrm{C}$. An indication for the vapour pressure of the targets was calculated to be 108 torr and 50 torr, respectively, using the Antoine Equation:

$$
\log _{10}(\mathrm{P})=\mathrm{A}-(\mathrm{B} / \mathrm{T}+\mathrm{C})
$$


where $P$ is the vapour pressure in bar and $T$ is the temperature in Kelvin. The constants $A, B$ and $C$ were obtained from the NIST chemistry webbook [32]. These constants were $A=5.20409, \mathrm{~B}=$ 1581.341 and $\mathrm{C}=-33.5$ for methanol, and $\mathrm{A}=5.37229, \mathrm{~B}=1670.409$ and $\mathrm{C}=-40.191$ for ethanol.

An electron current of $20 \mu \mathrm{A}$ and operating pressures of $1-1.5 \times 10^{-6}$ torr were used for all of the data presented here. The linearity of the detected cation signal at these operating pressures and electron current was verified. It is not expected that there will be any significant mass dependent transmission of the QMS for the small mass range investigated here, that is 12 to $46 \mathrm{amu}$. However, an attempt was made to confirm this by comparing the relative peak heights of the mass spectrum of butanol (up to 74 $\mathrm{amu}$ ), measured under the same operating conditions, to those in the literature [32]. It was found that there is no observable mass dependence of the spectrometer over this range of masses, consistent with the findings of Zubek et al $[33,34]$ who employ the same model of QMS. For these experiments the retardation curves of the relevant fragment ions were measured to confirm that the kinetic energy of the fragments investigated was sufficiently low to ensure uniform extraction to the mass filter for all cations. The mass spectrum was found to be invariant for extraction voltages from 1- $4 \mathrm{e} \mathrm{V}$ and an extraction voltage of $3 \mathrm{eV}$ was used for these measurements. Finally, the uniformity of the electron beam intensity was checked over the energy range used to measure the partial ionisation cross sections (i.e., $10-100 \mathrm{eV}$ ) by measurements of the Argon $\mathrm{Ar}^{+}$partial ionisation cross section. This data was compared to that of Rejoub et al [35], as shown in figure 1. The data of Rejoub et al [35] demonstrate near perfect agreement with the long standing and well accepted standards of Rapp and EnglanderGolden [36] for all five of the noble gases, in terms of both shape and absolute magnitude, establishing their credibility as benchmark data. The agreement between the current data and that of Rejoub et al [35] is excellent, demonstrating that the appropriate optimisation and tuning of the spectrometer had been achieved.

The mass spectra for methanol and ethanol, as well as the residual background, were each measured on several separate days spanning this study. The background spectrum (an average for more than 10 cycles) was subtracted from the signal mass spectra (also an average of more than 10 cycles) to produce a signal minus background (S-B) for each measurement. These (S-B) spectra were normalised to the base peak (most intense peak) so as to negate any variations in the operating pressures used on the different days. The standard deviation on the relative cation abundances could then also be determined as the uncertainty of the relative abundances.

The ion efficiency curves, or partial ionisation cross sections (PICS), were measured for the parent cation and several cationic fragments for both methanol and ethanol by monitoring the count rate of the detected cation as the electron energy was scanned. For cationic masses with a contribution from 
the background of more than $1 \%$, the background PICS was subsequently subtracted. The PICS reported in section 3.2 are averaged over many measurements. Each PICS data consists of at least 5 measurements spanning the total collection period for the relevant target. Each measurement was the mean of 10 energy cycles. The mean of each 10 cycle measurement was normalized to unity and the PICS data is then the mean of all the cycles from all the measurements, up to 70 cycles in total. The uncertainty of each datum point is the standard deviation of the mean of all of the cycles (typically 1$2 \%$ ). Relative PICSs were determined using the contribution of each cation to the mass spectra, which were measured at an electron energy of $70 \mathrm{eV}$. The errors on the relative PICS reflect the standard deviation in the repeated measurements and the uncertainty in the relative contributions to the mass spectra.

A sum of the relative PICS for all the cations yields the total ionisation cross section (TICS). The TICS obtained from this study were normalised to the absolute value of Rejoub et al. [21] at $70 \mathrm{eV}$. Subsequently, the absolute values of all of the PICS could also be determined from their relative contributions to the TICS. As a consequence of this normalisation, the current TICS and PICS also inherit the uncertainty in the absolute absolute data of Rejoub et al. [21] at $70 \mathrm{eV}$ (i.e. 6\%) in addition to the standard deviation in the repeated measurements and the uncertainty in the relative contributions to the mass spectra. The total errors are determined by a quadrature sum of the contributing errors.

At the threshold for the appearance of an ion fragment, the ion signal should follow the Wannier Law. After correcting for any background contributions, the appearance energies (AE) can be determined by fitting the relevant cation intensity data of counts verses impact energy, $E$, at energies close to threshold with the function:

$$
f(E)=\left\{\begin{array}{c}
E<A E: 0 \\
E \geq A E: \int_{0}^{\infty} e^{\frac{-\left(E-E_{0}\right)^{2}}{2 \sigma^{2}}}\left[a(E-A E)^{p}\right] d E
\end{array},\right.
$$

where $A E$ is the appearance energy, $a$ is a scaling factor, $p$ is the Wannier exponent and the integral convolutes the exponential function with a Gaussian function to account for the energy resolution of the internal electron beam. Here $E_{0}$ is the energy at the peak of the Gaussian and $\sigma$ is related to its full-width-half-maximum (FWHM). The fitting was performed in LabView [37], using a non-linear fit by employing the Marquart-Levenberg algorithm. 
The appearance energy of argon was used to calibrate the energy scale as well as to determine the energy resolution of the electron beam. By noting that the Wannier exponent, $p$, of argon is well established to be 1.127 [38], equation (2) can be fitted to the experimental data with $p$ being a fixed parameter and the value of $\sigma$ a variable of the fit. This method revealed that the energy resolution for these measurements is $\sim 0.8 \pm 0.05 \mathrm{eV}$, when using data up to $2 \mathrm{eV}$ above $A E$. Studies have shown that this approach is valid for energies up to $\sim 3 \mathrm{eV}$ above the threshold [39]. Using simpler atomic targets it has been shown that the range of validity of the Wannier equation varies for different targets, for example, the Wannier equation is valid for $2 \mathrm{eV}$ above threshold for argon and extends to $5 \mathrm{eV}$ above threshold for neon [40]. All of the appearance energies for methanol and ethanol presented here were calculated using data $\sim 2 \mathrm{eV}$ above $A E$. Indeed, the $A E$ was calculated for many different data ranges from $A E+1.5 \mathrm{eV}$ to $A E+2.5 \mathrm{e} \mathrm{V}$ to observe the variation and establish an uncertainty for the reported $A E \mathrm{~s}$. The uncertainty in the determined $A E \mathrm{~s}$ would be, at best, $\pm 0.5 \mathrm{eV}$ given the modest energy resolution of the electron source and the variation in the determined $A E$ value with the energy range chosen.

\section{Results and Discussion}

\subsection{Mass Spectra}

The mass spectra produced from electron impact ionisation of methanol and ethanol using $70 \mathrm{eV}$ electrons are shown in figure 2. The mass resolution of the QMS is demonstrated in figure $2 \mathrm{c}$, where it can be seen that adjacent peaks of $1 \mathrm{amu}$ separation are clearly resolved. As these targets are small and relatively uncomplicated, many of the cationic fragments can be unambiguously identified and have been labelled on the figures, particularly those with high intensities. Further details of the cation identities are given in section 3.2.

For both targets the most intense peak observed is for the oxonium ion $\left(\mathrm{CH}_{2} \mathrm{O}^{+} \mathrm{H}\right)$ with a mass of 31 amu. This ion is a signature of primary alcohols [41] and has a resonance stabilized structure which is a contributing factor to its intensity [42]. It is interesting to note that the parent ion in ethanol $(\mathrm{m} / \mathrm{z}=$ $46)$ is significantly smaller in intensity than that in methanol $(\mathrm{m} / \mathrm{z}=32)$, indicating that fragmentation is more spontaneous in the larger alcohol. The relative contributions of the $\mathrm{OH}^{+}, \mathrm{H}_{2} \mathrm{O}^{+}$and $\mathrm{H}_{3} \mathrm{O}^{+}$ cations are considerably larger in ethanol than methanol, consistent with the observations from other studies [32].

The relative cation abundances, with respect to the base peak at $\mathrm{m} / \mathrm{z}=31$, are given in tables 1 and 2 . Also given in the tables are the standard deviations on the relative abundances as well as the background contribution to each cation. The percentage background column indicates that there are 
only a few masses where the contribution from the background is above $1 \%$. This is important when analysing the PICS data. Let us now concentrate on the methanol results first. The methanol data from this study compares quite well with the relative ratios from NIST [32] and Srivastava et al [20]. There are, however, some rather dramatic differences between the data obtained in this study and those of Douglas and Price [26] and Cummings and Bleakney [28]. For example, these two authors report larger contributions of $29 \mathrm{amu}$. Douglas and Price [26] also reported substantially larger contributions from the cations with masses $=12-16 \mathrm{amu}$, which correspond to $\mathrm{C}^{+}, \mathrm{CH}^{+}, \mathrm{CH}_{2}^{+}$and $\mathrm{CH}_{3}{ }^{+}$. Note that the data from NIST gives a much smaller contribution from these masses. Also the data of Cummings and Bleakney [28] shows an extremely large intensity at 28 amu, which may indicate some atmospheric contamination giving cations to $\mathrm{N}_{2}^{+}$or $\mathrm{CO}^{+}$. Alternatively, it has been suggested that methanol thermally decomposes when close to the hot filament to produce CO. The cation at mass $28 \mathrm{amu}$ could then arise from the ionization of $\mathrm{CO}$ produced as a degradation product, rather than being an indication of contaminants. Likewise, the data of Szot et al [43] has a very large intensity at $18 \mathrm{amu}$, a relative abundance of 32 , rather than $\sim 1$ for the other data presented in table 1 . This may indicate the presence of $\mathrm{H}_{2} \mathrm{O}$ contamination in their sample.

A similar trend is seen in table 2 for the data of ethanol. For example, the data of Szot et al [44] shows increased intensity at masses usually associated with atmospheric contamination. The present data indicates that there is a somewhat higher contribution for 12-15 amu, otherwise, the data from this study compares reasonably well with that from NIST [32].

\subsection{Appearance Energies and Cation Assignments}

\subsubsection{Methanol}

Methanol is a small molecule yielding a relatively simple mass spectrum resulting from electron impact ionisation and fragmentation. Further, the fragmentation of methanol has been studied previously [20,28] and the identity of the various cations have been largely determined taking into account the $\mathrm{m} / \mathrm{z}$, appearance potential and utilising Hess's Law.

The molecular weight of methanol is $32 \mathrm{amu}$. The parent cation, usually denoted $\mathrm{M}$, therefore should be seen with a mass/change ratio of 32 within the mass spectrum. The lowest energy electrons within the methanol molecule are those in the non-bonded orbital on the oxygen atom. Therefore, it is reasonable to expect that one of these electrons is removed to form the parent ion at $32 \mathrm{amu}$ with the 
residual positive charge on the oxygen atom. The $A E$ determined in this study, $10.7 \pm 0.5 \mathrm{eV}$ is in good agreement with the first ionisation potential of methanol, i.e., $10.84 \mathrm{eV}$ [32].

As noted earlier, the cation of mass 31 is attributed to the oxonium ion where the proton has been removed from the carbon atom, rather than the oxygen atom. This assignment is supported by isotopic experiments with $\mathrm{CH}_{3} \mathrm{OD}$ [45]. The oxonium ion is resonance stabilised and therefore it is expected that the cross section for the formation of this cation will be high, as the cross section also depends on the stability of the products. The high intensity of $\mathrm{m} / \mathrm{z}=31 \mathrm{amu}$ indicates that the bond breaking is both rapid and spontaneous. The cation of $\mathrm{m} / \mathrm{z}=30 \mathrm{amu}$ can be attributed to the formaldehyde ion. Furthermore, the identity of masses $12-15$ amu have been attributed to $\mathrm{C}^{+}, \mathrm{CH}^{+}, \mathrm{CH}_{2}{ }^{+}$and $\mathrm{CH}_{3}{ }^{+}$, respectively. In addition to these readily expected ions, figure 2a shows a small intensity at $\mathrm{M}+1$ which can be seen at $\mathrm{m} / \mathrm{z}=33$. The relative intensity of this cation with respect to that of $\mathrm{M}$, is consistent with the natural isotope abundance of carbon. Finally, cations can also be seen at $\mathrm{m} / \mathrm{z}=1-3$ amu and 17-19 amu. These signals can be attributed to $\mathrm{H}^{+}, \mathrm{H}_{2}^{+}, \mathrm{H}_{3}^{+}$and $\mathrm{OH}^{+}, \mathrm{H}_{2} \mathrm{O}^{+}, \mathrm{H}_{3} \mathrm{O}^{+}$, respectively.

Figure 3 shows a typical example of the experimental data measured to determine the appearance energy, in this case for the parent ion of methanol. Also displayed on the figure is the fit to the data obtained from equation 2. This figure clearly demonstrates the effect of the energy resolution of the incident electron source, showing intensity at lower energies than the values of $A E$ determined by the fits which in turn results in the data appearing, by eye, to have a lower $A E$. This highlights the need to accurately include the energy resolution in the fitting procedure and the difficulty in simply 'estimating' the $A E$ directly from the data. The six appearance energies obtained, for the most intense peaks within the mass spectrum, are listed in table 3, along with those from Srivastava et al [20], Zavilopulo et al [27] and Cummings and Bleakney [28] in addition to those compiled by NIST [32]. The present data is in quite good accord with those within the literature, with the exception from Srivastava et al [20] whose $A E \mathrm{~s}$ are consistently larger by $\sim 2-3.5 \mathrm{eV}$ than those of the other sources. The exception is the present $A E$ for 29 amu which is $\sim 3 \mathrm{eV}$ lower than reported by the other studies. However, if the data of Srivastava et al [20] were corrected for its systematic energy shift then in fact its $A E$ for $29 \mathrm{amu}$ would be in satisfactory agreement with the present value. Nontheless, based on an $A E$ of $=14-14.6 \mathrm{eV}$, as shown in table 3, the ion observed at $29 \mathrm{amu}$, is most likely to be $\mathrm{CO}^{+} \mathrm{H}$.

\subsubsection{Ethanol}

Ethanol is a slightly larger molecule than methanol, but many of the same trends we have just described equally apply to this molecule as for methanol. However, the structure of some of its cations cannot be unambiguously assigned simply based on their $\mathrm{m} / \mathrm{z}$ and appearance energy. For this reason we have used the molecular formula only when referring to some cations, rather than their 
structure. The group of cations seen between masses 41-46 amu can be attributed to the sequential loss of a $\mathrm{H}$ atom from the parent ion. It is reasonable to conclude that the parent ion is formed by removal of one of the lone-pair electrons from the oxygen atom, as these electrons have the lowest ionisation potential (10.48 eV [32]). Similar to methanol, the M-1 structure would be the resonance stabilized $\mathrm{CH}_{3} \mathrm{CHO}^{+} \mathrm{H}$ ion at $45 \mathrm{amu}$ while $44 \mathrm{amu}$ is the acetaldehyde ion. The base peak at $31 \mathrm{amu}$ is certainly the oxonium ion as ethanol is also a primary alcohol. The identity of the peak at $\mathrm{m} / \mathrm{z}=29$ could be $\mathrm{CO}^{+} \mathrm{H}$ or $\mathrm{C}_{2} \mathrm{H}_{5}{ }^{+}$. The series of cations below $\mathrm{m} / \mathrm{z}=28$ correspond to sequentially removing a $\mathrm{H}$ atom from ethene $\left(\mathrm{C}_{2} \mathrm{H}_{4}{ }^{+}\right)$. Again, similar to methanol, the peaks from $19-17 \mathrm{amu}, 15-12 \mathrm{amu}, 2$ amu and 1 amu can be assigned to the $\mathrm{H}_{3} \mathrm{O}^{+}, \mathrm{H}_{2} \mathrm{O}^{+}, \mathrm{OH}^{+}, \mathrm{CH}_{3}{ }^{+}, \mathrm{CH}_{2}{ }^{+}, \mathrm{CH}^{+}, \mathrm{C}^{+}, \mathrm{H}_{2}^{+}$and $\mathrm{H}^{+}$cations, respectively. Finally, the intensity of the peak at $47 \mathrm{amu}$ is consistent with the natural isotope of carbon for the parent peak.

The appearance energies for some of the cations of ethanol were determined using the approach described previously and are shown in table 4 . For some cations the agreement with other values in the literature is quite good, however for other cations the fitted values are discordant by more than 2 $\mathrm{eV}$. In both cases the respective fits to our data looks accurate. This highlights the need for careful measurement and subtraction of the background signal, since the fit is weighted by $1 / \mathrm{N}$ thus giving emphasis to the energy region with low counts. This also highlights the general difficulty in extracting $A E \mathrm{~s}$ in molecules. The form of equation (2) has been established as being valid in some atoms, however for molecules the exponential $p$ has no established physical meaning and the reliability of this method to extract $A E$ s from molecules is only through comparison of such results with spectroscopic data for a range of small molecules [46].

\subsection{Ionisation Cross Sections}

\subsubsection{Methanol}

Partial ionisation cross sections (PICS) were measured for 9 cation masses of methanol. These 9 masses were in the ranges 12-15 amu and 28-32 amu and constitute $96 \%$ of the cations generated by electron impact with $70 \mathrm{eV}$ electrons. The PICS for $\mathrm{H}^{+}$and $\mathrm{H}_{2}{ }^{+}$, which constitute the majority of the remaining ion signal, $2.4 \%$ of the total, were excluded from the PICS we report as it is extremely difficult to obtain accurate results for very light fragments with a high mass instrument such as that used here [47]. Additionally, the lighter fragments typically have higher velocities to conserve energy and momentum during the fragmentation, such that their collection efficiency may not be $100 \%$ when employing the same apparatus conditions used to collect the other fragments. Considering these ions constitute only a small fraction of the total ion yield collected here, it was decided we should deliver accurate measurements of the ions produced with high intensity rather than to present possibly dubious results for all of the ions observed. Further, the PICS for $\mathrm{H}_{2} \mathrm{O}^{+}$and $\mathrm{OH}^{+}$are not reported as 
these signals are small and contain a very high background contribution, $\sim 70-85 \%$. By summing the PICS for the nine cations we considered, an indication of the total ionisation cross section (TICS) can be obtained. The present TICS has been normalised to the absolute measurement of Rejoub et al. [21], in order to establish an absolute scale for the present data. The data of Rejoub et al. [21] does not explicitly give a datum point at $70 \mathrm{eV}$, rather an interpolation of their data has been used. Establishing an absolute value for the TICS subsequently allows absolute values for all of our partial ionization cross sections to be assigned, and as such a more stringent comparison to other results in the literature can be made. The absolute PICS for the nine ions measured, and the TICS, are given in table 5, while figures 4, 5 and 6 present our data and provide a comparison to that available within the literature.

The present TICS data in figure 4a demonstrates quite good agreement with that of Srivistava et al [20] and Rejoub et al [21], although the present data overestimates the magnitude of the cross section compared to that of Rejoub et al [21] at energies below $50 \mathrm{eV}$. Further, the present TICS seems to decrease at a faster rate than that of the others at energies above $60 \mathrm{eV}$. This latter observation is almost certainly due, at least in part, to the fact that our results do not include any contribution from the $\mathrm{H}^{+}$and $\mathrm{H}_{2}{ }^{+}$ions. It can be seen from Rejoub et al [21], Srivastava et al [20] and Pal [24] that the contributions of these ions to the total cross section is mainly at those higher energies. Indeed, if the PICS of Rejoub et al [21] for $\mathrm{H}^{+}$and $\mathrm{H}_{2}{ }^{+}$are added to the present data then the agreement is markedly improved in this energy region. All of the theoretical curves in figure $4 \mathrm{~b}$ show acceptable agreement with the experimental data. The predication of Pal using the Jain and Khare semi-empirical formulation [24] and the Binary Encounter Bethe (BEB) model from Hudson et al [22] yield accurate results over the full range of data. However, it is the spherical complex optical potential (SCOP) calculation of Vinodkumar et al [25] that provides the best agreement with the present data, particularly for low energies. Indeed it only deviates from the present data at energies above $60 \mathrm{eV}$, where it is expected that our results somewhat underestimate the TICS due to the omission of the contribution from the light cations.

Figure 5 shows the current PICS data compared to that of Srivastava et al [20] and Pal [24] for individual masses. All of the PICS show similar characteristics of a rapid 'turn on' from threshold followed by a quite uniform intensity. Note that the energy at which the ions first begin to appear has been characterised by the appearance energies we presented in section 3.2. While the shape of the PICS may not exhibit any interesting structure, these measurements are nonetheless important as they demonstrate the relative probability of each dissociative ionisation channel at various energies. This is essential for input into modelling applications where the identity of the cationic products are of importance, or where interactions between electrons and matter are tracked [48]. The present data are generally in good accord with the only other experimental measurements, and also the theoretical 
predications. The most obvious exception to this general statement is for the $\mathrm{CO}^{+}$cation, of mass 28 amu, where the theory is much lower in magnitude than that seen in both experimental studies. This could indicate that much of the intensity seen in the present $28 \mathrm{amu}$ data is due to thermal decomposition of methanol by the hot filament, rather than by dissociative ionisation. The present experimental data of this cation has large error bars, which arise from the poor reproducibility of the relative contribution this ion makes to the mass spectrum. This, together with the large background contribution to this mass $(\sim 10 \%)$, makes the present data somewhat less reliable for this cation. As noted with respect to the mass spectrum, there is a significant difference between the experimental measurements for the cations of masses 12-15 amu. Additionally, for the $\mathrm{C}^{+}$cation, the theory predicts a much higher appearance potential than is seen in either of the experimental measurements. Finally, the theoretical data also predicts a much shallower slope in the counts versus energy, for low energies, for $32 \mathrm{amu}\left(\mathrm{CH}_{3} \mathrm{O}^{+} \mathrm{H}\right), 31 \mathrm{amu}\left(\mathrm{CH}_{2} \mathrm{O}^{+} \mathrm{H}\right)$ and particularly for $30 \mathrm{amu}\left(\mathrm{CH}_{2} \mathrm{O}^{+}\right)$. This is evidenced by the theoretical predictions underestimating the measured cross sections at energies below $\sim 40 \mathrm{eV}$.

As a consequence of the limited mass resolution in the apparatus employed by Rejoub et al [21], the present data for similar masses needs to be summed in order to directly compare to results given by Rejoub et al [21]. This is shown in figure 6. Note that the group of ions labelled $\mathrm{CH}_{\mathrm{n}} \mathrm{O}^{+}$contains the cations of masses 28-32 amu. Quite good agreement is seen between the data sets for $\mathrm{CH}_{\mathrm{n}} \mathrm{O}^{+}$, although the the present data is higher in magnitude than the other two sets. Nonetheless our results are well within the experimental uncertainty of Srivastava et al [20]. The group of ions labelled $\mathrm{CH}_{\mathrm{n}}^{+}$ $+\mathrm{H}_{\mathrm{n}} \mathrm{O}^{+}$contain ions from mass 12-18 amu for Rejoub et al [21], but only for 12-15 amu for the present data and that of Srivastava et al [20] as the PICS were not measured for ions of mass 16-18 amu. The theoretical calculations of $\mathrm{Pal}[24]$ include the cations $\mathrm{OH}^{+}, \mathrm{CH}_{3}{ }^{+}, \mathrm{CH}_{2}{ }^{+}, \mathrm{CH}^{+}$and $\mathrm{C}^{+}$. It is, therefore, not unexpected that the data of Rejoub is higher than the others given that it includes more cations. However, there is still quite good qualitative agreement between the various data sets in terms of the cross section shape and appearance energy.

\subsubsection{Ethanol}

For ethanol, PICS were measured for 19 cationic masses of 12-16 amu, 25-32 amu and 41-46 amu which account for $90 \%$ of the total ions measured within the mass spectrum at $70 \mathrm{eV}$. Note that the normalisation of the TICS was again performed at $70 \mathrm{eV}$, but only the cations from $24-46 \mathrm{amu}$ were included as the lower mass cations include those from the water impurity within the present target source (95\% ethanol from Sigma Aldrich). In this case, the PICS of Rejoub et al. [21] for the ion groupings of $\mathrm{C}_{2} \mathrm{H}_{\mathrm{n}} \mathrm{O}^{+}$and $\mathrm{CH}_{\mathrm{n}} \mathrm{O}^{+}+\mathrm{C}_{2} \mathrm{H}_{\mathrm{n}}^{+}$were used as the normalisation. The total ionisation cross section is given in figure 7, where it can be seen that the present data agrees very well with that of Rejoub et al [21] up to energies of $\sim 60 \mathrm{eV}$. However, at higher energies present cross section is seen 
to decrease with energy faster than that of Rejoub et al [21]. Also shown in figure 7 is the PICS for $\mathrm{H}^{+}+\mathrm{H}_{2}{ }^{+}$from Rejoub et al [21], which indicates that the aforementioned discrepancy seen in the TICS at high energies could simply be due to the fact that the present TICS does not include these small ions. The same trend can be seen here as was observed earlier in figure $4 \mathrm{a}$, in that the data of Hudson et al [22] underestimates the magnitude of the other experimental data at lower energies. Further, the DM calculation [22] significantly overestimates the magnitude of the cross section while the BEB calculation [22] is in very good agreement with the data of Hudson et al at low energies but consistently underestimates the magnitude of the data from the other sources. Similar to what we found in methanol, we observe that the recent calculations of Vinodkumar et al [25] are in excellent agreement with the present data at lower energies, but deviate at energies $>50 \mathrm{eV}$ to correspond well to the TICS of Rejoub et al [22].

The individual PICS for ethanol are given in figure 8 and tabulated in table 6, while the summed PICS for ions of similar mass are given in figure 9. Note that the data embodied in figure 8 and table 6 are original, and that there are no independent experimental and theoretical cross sections against which we can compare them. Interestingly, figure 8 does indicate all the PICS here exhibit similar qualitative energy behaviour and are virtually without any structure but that the rate of their rise in magnitude from threshold does vary for different $\mathrm{m} / \mathrm{q}$. The summed PICS are for the masses 41-46 amu which are denoted by $\mathrm{C}_{2} \mathrm{H}_{n} \mathrm{O}^{+}$, and for 24-32 amu which are denoted by $\mathrm{CH}_{n} \mathrm{O}^{+}+\mathrm{C}_{2} \mathrm{H}_{n}{ }^{+}$. Further, Rejoub et al [21] gives data from 12-18 amu, denoted by $\mathrm{CH}_{\mathrm{n}}{ }^{+}+\mathrm{H}_{\mathrm{n}} \mathrm{O}^{+}$, whereas the corresponding present data only contains masses in the range 12-16 amu, or for $\mathrm{CH}_{\mathrm{n}}{ }^{+}$. As can be seen in figure $9 \mathrm{~b}$, the present cross section is in excellent agreement with that of Rejoub et al [21] for the summed PICS of $\mathrm{CH}_{\mathrm{n}} \mathrm{O}^{+}+\mathrm{C}_{2} \mathrm{H}_{\mathrm{n}}^{+}$which contains the majority of the total cross section $(\sim 60 \%)$. Our data is slightly higher in magnitude for the heaviest group of masses, as shown in figure 9a, but is within the experimental uncertainty, except for energies between $35-55 \mathrm{eV}$. Finally, the present data is significantly lower in magnitude for the lighter group of masses (see figure $9 \mathrm{c}$ ) which is not surprising due to the exclusion of the $\mathrm{H}_{n} \mathrm{O}^{+}$masses from the present data.

\section{Conclusions}

The direct ionisation and dissociative ionisation of methanol and ethanol by electron impact have been investigated using a quadrupole mass spectrometer. The appearance energies, for a number of the observed cations, were obtained and are generally in fair accord with those reported previously. An improvement to the $\mathrm{AE}$ determined for $\mathrm{m} / \mathrm{z}$ ratios where more than one cation is possible, for example ions with $\mathrm{m} / \mathrm{z}$ of 28-30, may be achieved by using multiple exponents to fit the data to account for this. Partial ionisation cross sections have also been measured for methanol, which support some of the previous measurements and calculations available within the literature. The partial ionisation cross sections for individual cations of ethanol are reported here for the first time. When summed to give 
either the total ionisation cross sections, or PICS for groups of cations of similar mass, the present measurements in both methanol and ethanol are in reasonable agreement with previous results in the literature. This level of agreement in methanol and ethanol gives us confidence that further studies on larger alcohols might also be made with some accuracy.

\section{Acknowledgement}

K.L.N. thanks CNPq for an "Attracting Young Talent Grant" under the "Science Without Borders" program. M.C.A.L. acknowledges financial support from CNPq and FAPEMIG, while M.J.B. thanks $\mathrm{CNPq}$ for his "Special Visiting Professor" award. R.F.C.N. and H.V.D. acknowledge $\mathrm{CNPq} / \mathrm{CAPES} / \mathrm{CsF}$ and Flinders University for financial assistance. D.B.J. thanks the ARC for a Discovery Early Career Researcher Award. 


\section{References}

1. MI Hoffert, K Caldeira K, G Benford, DR Criswell, C Green, H Herzog, AK Jain, HS Kheshgi, KS Lackner, JS Lewis, HD Lightfoot, W Manheimer, JC Mankins, ME Mauel, LJ Perkins, ME Schlesinger, T Volk and TM Wigley Science (2002) 298981.

2. TA Boden, G Marland and RJ Andres Global, Regional, and National Fossil-Fuel CO2 Emissions (2010) Carbon Dioxide Information Analysis Center, Oak Ridge National Laboratory, U.S.A. doi 10.3334/CDIAC/00001_V2010

3. Economics of Greenhouse Gas Limitations (1999) UNEP Collaborating Centre on Energy and Environment, Riso National Laboratory, Denmark

4. Reducing emissions from transport, European Commission (2015) http://ec.europa.eu/clima/policies/transport/index_en.htm

5. J Goldemberg Biotechnology for Biofuels (2008) 14096

6. JB Heywood Internal Combustion Engine Fundamentals (1989) MacGraw-Hill, New York

7. F Schmieder Z. Elektrochem. Angew. Phys. Chem. (1930) 36700

8. O Sueoka, Y Katayama and S Mori At. Coll. Res. Japan Prog. Rep. (1985) 1117

9. C Szmytkowski and AM Krzysztofowicz J. Phys. B: At. Mol. Opt. Phys. (1995) 284291

10. M Vinodkumar, C Limbachiya, KN Joshipura, B Vaishnav and S Gangopadhyay J. Phys. Conf. Ser. (2008) 115012013

11. DGM Silva, T Tejo, J Muse, D Romero, MA Khakoo and MCA Lopes J. Phys. B: At. Mol. Opt. Phys. (2010) 43015201

12. XM Tan and DH Wang Nucl. Instrum. Methods Phys. Res. B (2011) 2691094

13. MT Lee, GLC de Souza, LE Machado, LM Brescansin, AS dos Santos, RR Lucchese, RT Sugohara, MGP Homem, IP Sanches and I Iga J. Chem. Phys. (2012) 136114311

14. M Vinodkumar, C Limbachiya, A Barot and N Mason Phys. Rev. A (2013) 87012702

15. D Bouchiha, JD Gorfinkiel, LG Caron and L Sanche J. Phys. B: At. Mol. Opt. Phys. (2007) 40 1259-70

16. MA Khakoo, J Blumer, K Keane, C Campbell, H Silva, MCA Lopes, C Winstead, V KcKoy, RF da Costa, LG Ferrira, MAP Lima and MHF Bettega Phys. Rev. A (2008) 77042705

17. RT Sugohara, MGP Homem, IP Sanches, AF de Moura, MT Lee and I Iga Phys Rev A (2011) 83032708

18. K Varela, LR Hargreaves, K Ralphs, MA Kakoo, C Winstead, V McKoy TN Rescigno and AE Orel J. Phys. B: At. Mol. Opt. Phys. (2015) 48115208

19. N Duric, I Cadez, and MV Kurepa, Fizika (1989) 21, 339

20. SK Srivastava, E Krishnakumar, AF Fucaloro, and T van Note J. Geophys. Res. (1996) 101, 26155

21. R Rejoub, CD Morton, BG Lindsay, and RF Stebbings J. Chem. Phys. (2003) 118, 1756

22. JE Hudson, ML Hamilton, C Vallance, and PW Harland Phys. Chem. Chem. Phys. (2003) 53162

23. H.Deutsch, K Becker, R Basner, M Schmidt and TD Märk J. Phys. Chem. A (1998) 1028819.

24. S Pal Chem. Phys. (2004) 302119

25. M Vinodkumar, K Korot and PC Vinodkumar Int. J. Mass. Spectrom. (2011) 30526

26. KM Douglas and SD Price J. Chem. Phys. (2009) 131224305

27. AN Zavilopulo, FF Chipev and LM Kokhtych, Nucl. Instrum. Methods Phys. Res. B (2005) 233302

28. CS Cummings and W Bleakney Phys Rev (1940) 58787.

29. Hiden Analytical: http://www.hidenanalytical.com/en/

30. Sigma Aldrich: http://www.sigmaaldrich.com/brazil.html

31. MDC Vacuum Products, http://www.mdevacuum.com 
32. NIST webbook: NIST Chemistry WebBook, NIST Standard Reference Database Number 69, Eds. P.J. Linstrom and W.G. Mallard, http://webbook.nist.gov. [accessed August 2015]

Methanol permalink: http://webbook.nist.gov/cgi/inchi/InChI\%3D1S/CH4O/c1-2/h2H\%2C1H3

Ethanol permalink: http://webbook.nist.gov/cgi/inchi/InChI\%3D1S/C2H6O/c1-2-3/h3H\%2C2H2\%2C1H3

33. M Dampc, E Szymanska, B Mielewska and M Zubek J. Phys. B: At. Mol. Opt. Phys. (2011) 44055206

34. I Linert, M Dampc, B Mielewska and M Zubek Eur. Phys. J. D (2012) 6620

35. R Rejoub, BG Lindsay and RF Stebbings Phys. Rev. A (2002) 65042713

36. D Rapp and P Englander-Golden J. Chem. Phys. (1965) 431464

37. JY Beyon, (2001) LabVIEW: Programming, data acquisition and analysis. Upper Saddle River, NJ: Prentice Hall PTR

38. GH Wannier Phys Rev (1953) 90817

39. T Fiegele, G Hanek, I Torresm M Lezius and TD Mark J. Phys. B: At. Mol. Opt. Phys. (2000) 334263

40. J. B. Bluett, D. Lukić, and R. Wehlitz (2004) Phys. Rev. A 69042717

42. C Dass Fundamentals of Contemporary Mass Spectrometry (2007) John Wiley \& Sons, New Jersey

42. J Greaves and J Roboz Mass Spectrometry for the Novice, (2013) CRC Press, London

43. E Szot, L Wójcik and K G1uch Vacuum (2013) 90141

44. E Szot, K Gluch and L Wokcik Acta Physica Polonica (2013) 123797

45 MJS Dewar and W Thiel J. Am. Chem. Soc. (1977) 994907

46. S Denifl, S Ptasinska, B Gstir, P Scheier and TD Mark Int. J. Mass. Spectrom. (2004) 23299

47. Personal communications with the technical staff at Hiden (2015)

48. MC Fuss, L Ellis-Gibbings, DB Jones, MJ Brunger, F Blanco, A Munoz, P Limao-Vieira and G Garcia J. App. Phys. (2015) 117214701 


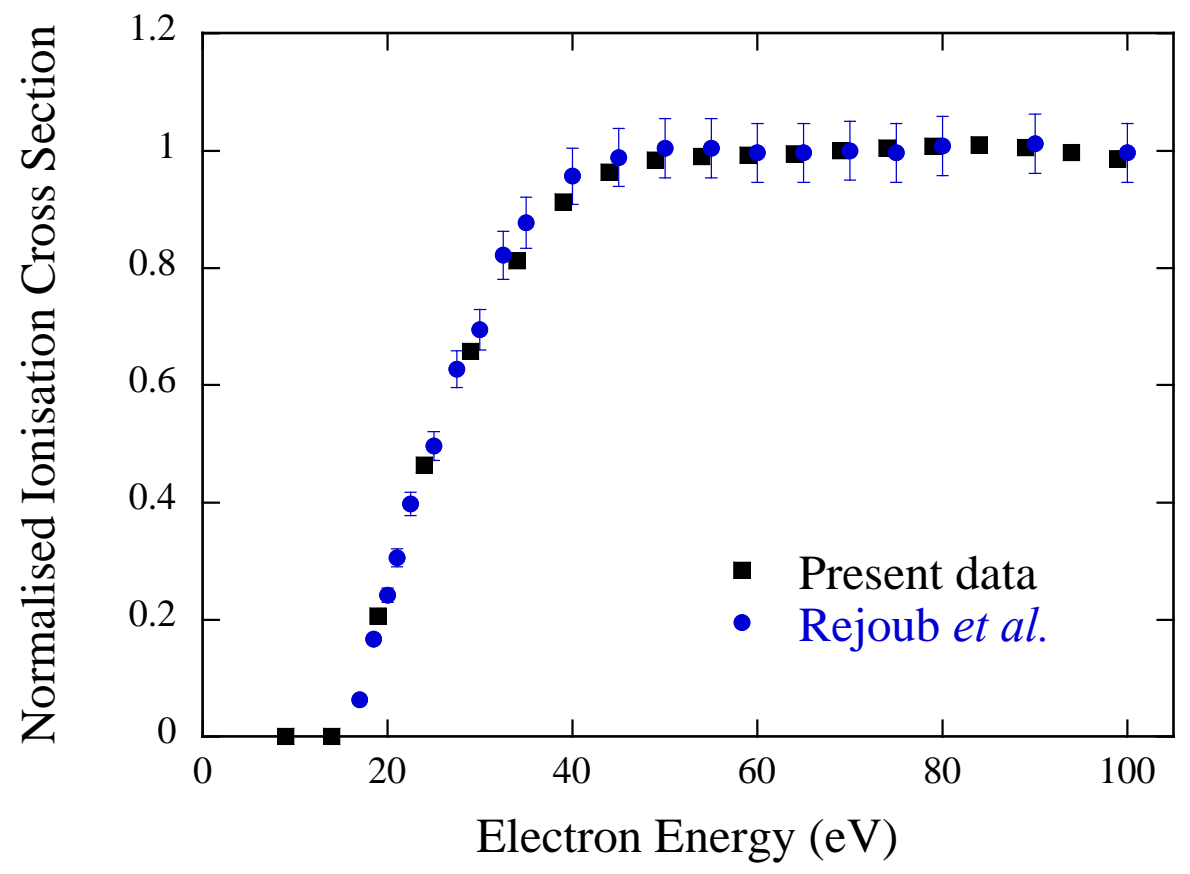

Figure 1: Comparison of the data obtained in this study (black squares) with the commonly accepted standards of Rejoub et al [35] (blue circles) for the single ionisation of Ar. Each of the data sets have been normalized to unity at $70 \mathrm{eV}$. This figure establishes that the present data are consistent with the benchmarked data. The error bars for the present data are $\sim 1 \%$ and so cannot be seen on this figure. 

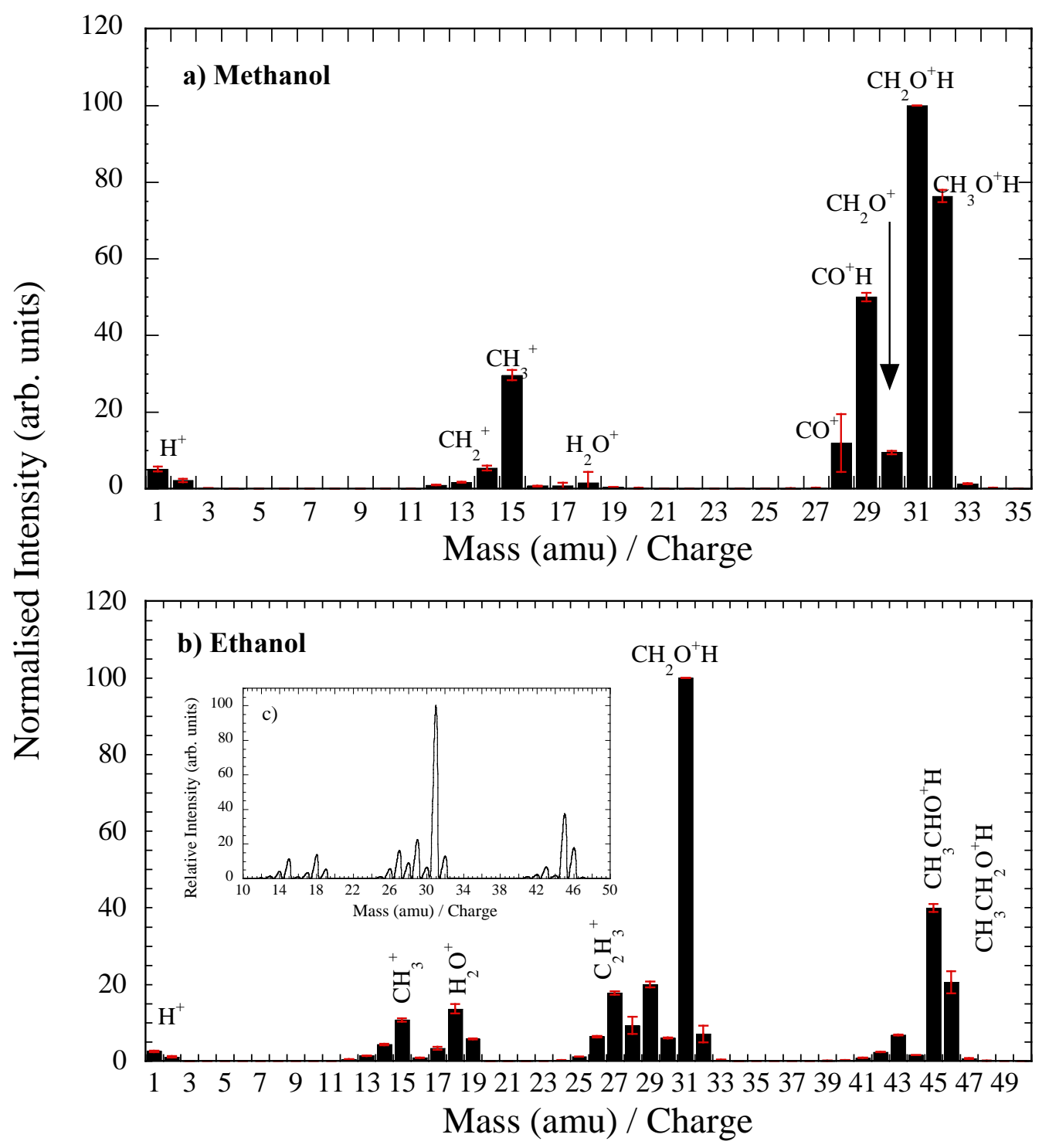

Figure 2: The mass spectra of cations produced by electron impact ionisation with electrons of $70 \mathrm{eV}$ for a) methanol and b) ethanol. For both molecules the signal and background spectra were measured on several occasions ( 5 for methanol and 7 for ethanol) with each spectra being the average of more than 10 measurements. On each occasion the background spectrum was subtracted from the signal spectrum to produce a (S-B) spectrum due to the target molecule only, and the base peak i.e. $\mathrm{m} / \mathrm{z}=31$ amu was normalised to 100 . The data in this figure shows the mean and standard deviation of the various (S-B) spectra providing the relative yield of each cation. An inset, c), demonstrates the mass resolution obtained in the current measurements. 


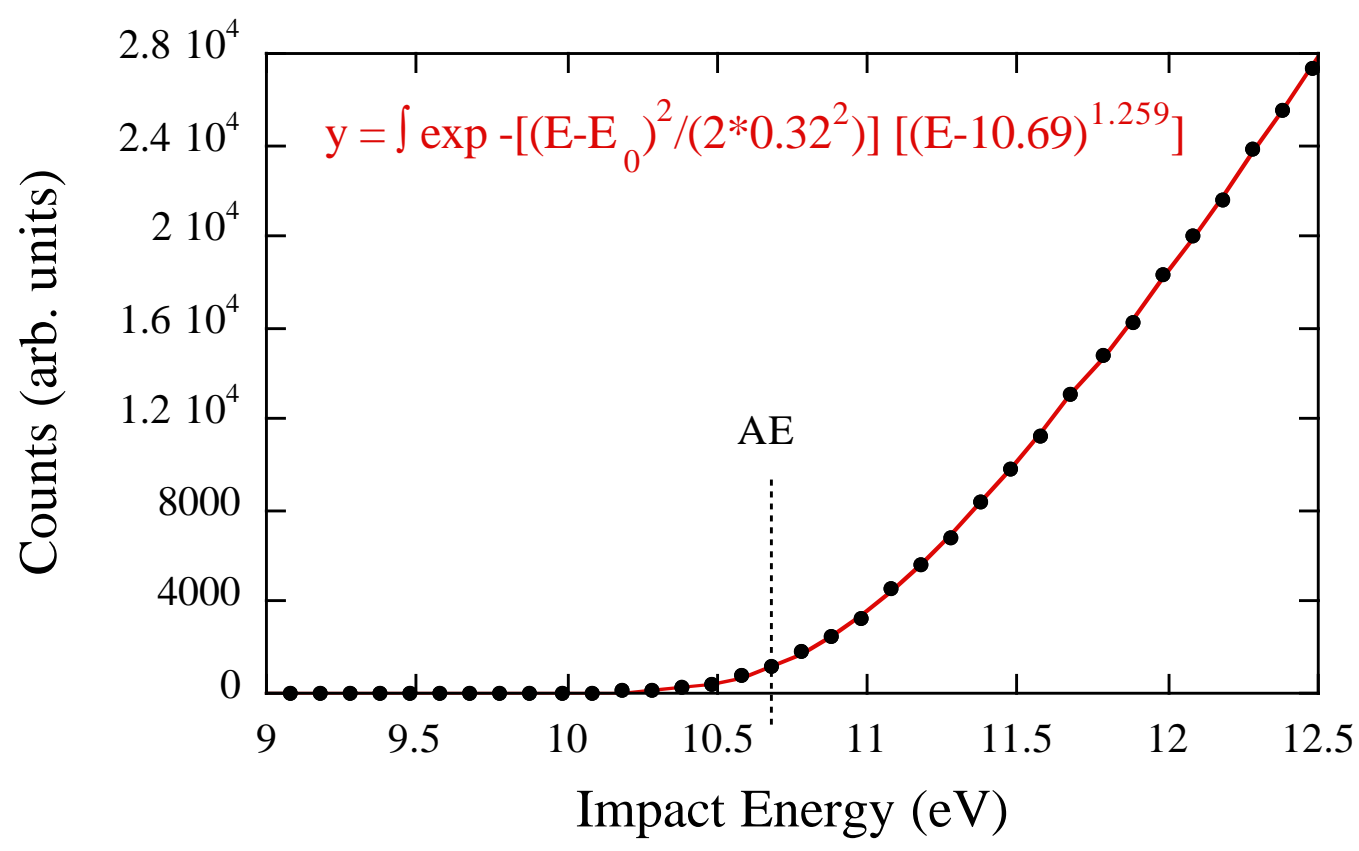

Figure 3: A typical example appearance energy measurement and fit for the parent cation of methanol (32 amu). The experimental data (black dots) are a measurement of the partial ionisation cross section within $2 \mathrm{eV}$ of threshold. The data have been fitted by the Wannier equation convoluted with a Gaussian function of FWHM $=0.8 \mathrm{eV}$, to account for the energy resolution of the electron beam, (see equation 2 in the text). The fit (red line) determines an appearance energy of $10.69 \mathrm{eV}$ and Wannier exponent of 1.259 . 

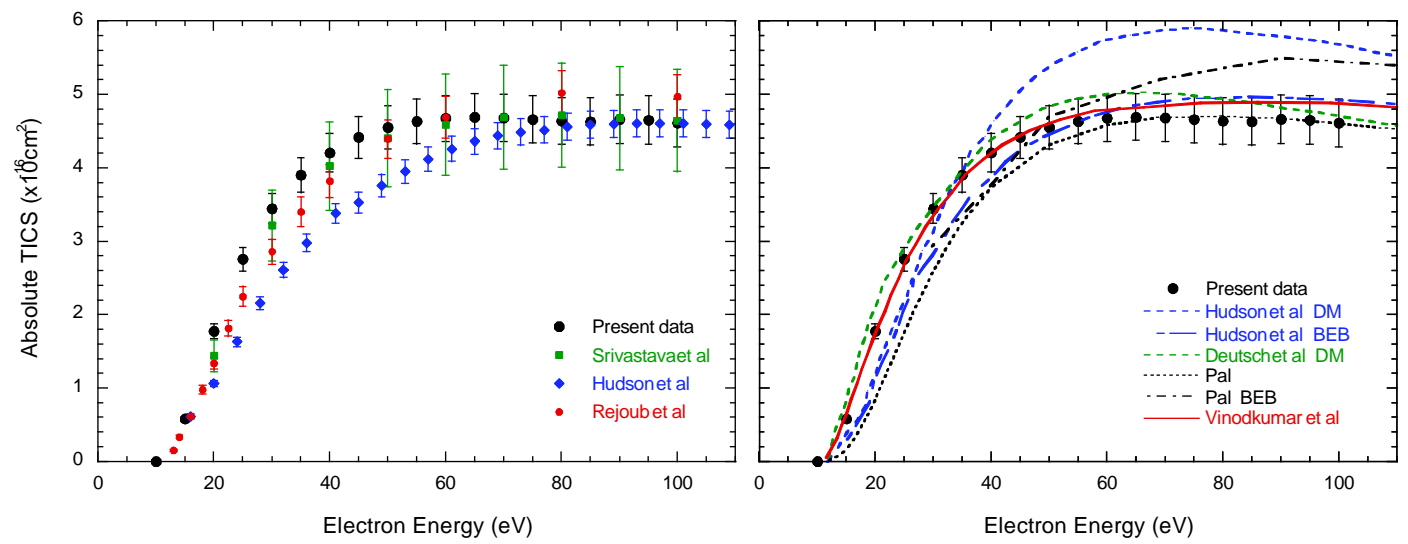

Figure 4: Total ionisation cross section (TICS) for methanol. a) shows a comparison of the current experimental data with that of other experimental studies while b) show a comparison of the current experimental data with that of other theoretical studies. The legends are given on the plots. See text for more details. 

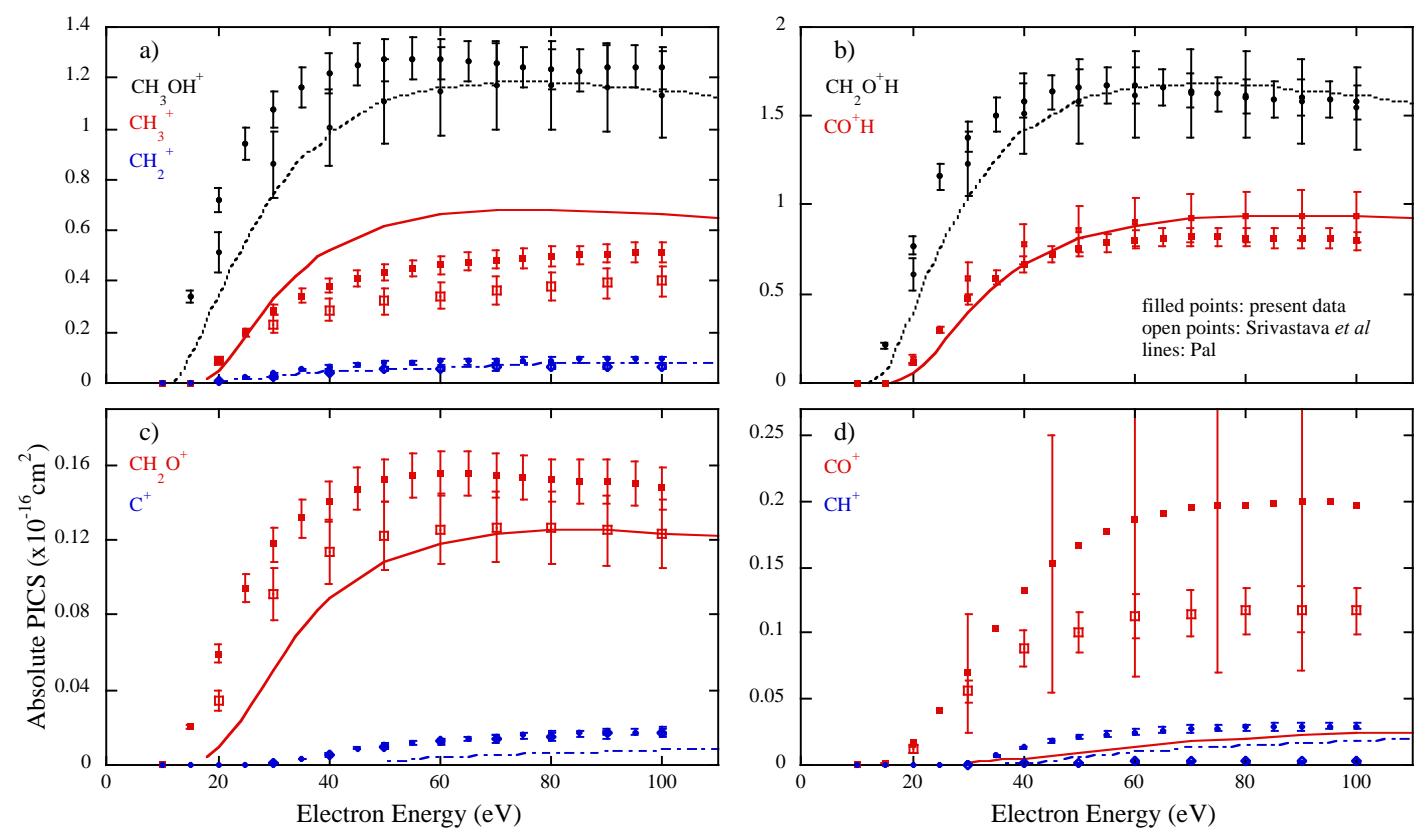

Figure 5: Absolute partial ionisation cross sections (PICS) for nine of the cations (denoted by their mass) produced from electron impact ionisation of methanol. The errors are the quadrature sum of the uncertainty in the experimental measurements of the cross sections, the uncertainty of the relative contributions to the mass spectrum and the normalisation to the absolute data of Rejoub et al [21]. In each graph the present data is shown in the filled symbols while the data of Srivastava et al [20] is represented with the open symbols and the theoretical predications [24] are shown as lines. The error bars for 28 amu (figure d) are $\sim 60 \%$ and have only been plotted on $1 / 3$ of the data points for clarity of the figure.
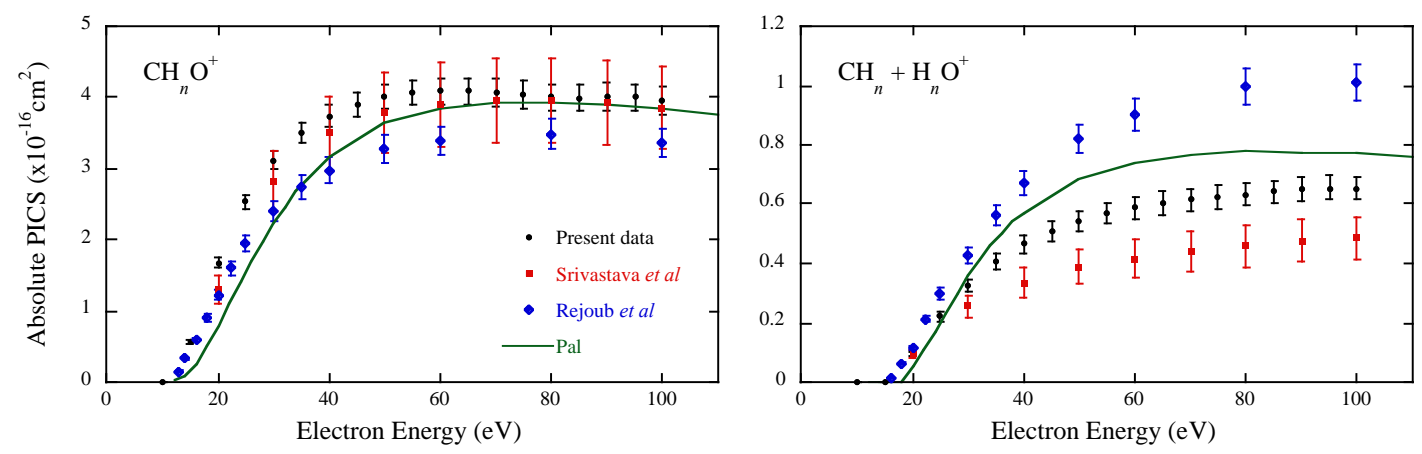

Figure 6: Summed PICS that directly correspond to the measurements of Rejoub et al [22]. See text for details. 


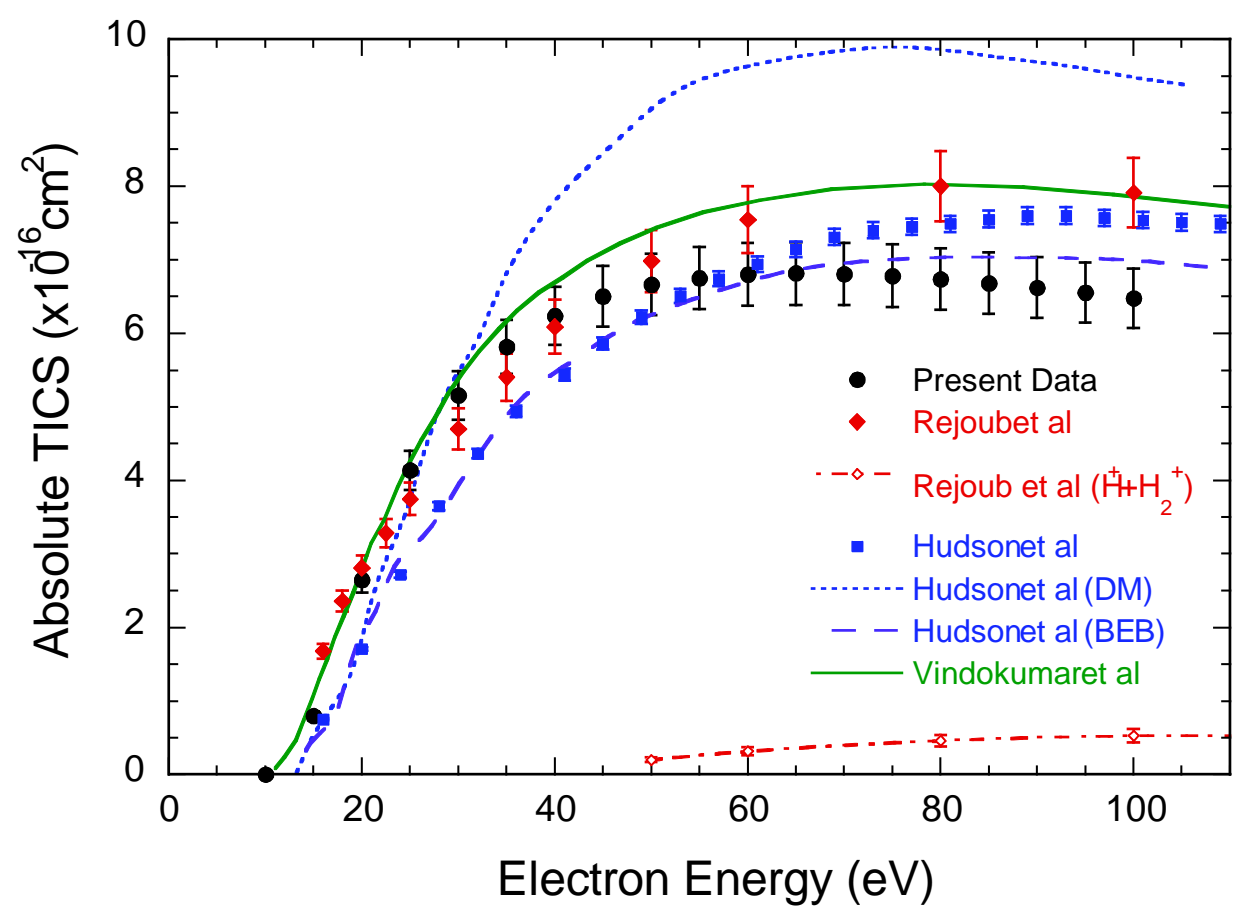

Figure 7: Total ionisation cross section (TICS) for ethanol showing a comparison between the experimental present data (black circles), that of Hudson et al [22] (blue squares) and Rejoub et al [21] (red diamonds). Also shown on the plot are two theoretical calculations from Hudson et al [22], namely using an additivity method (DM, blue dotted line) and a Binary Encouter Bethe model (BEB, blue dashed line), as well as the theoretical SCOP prediction from Vinodkumar et al [25]. The PICS for $\mathrm{H}^{+}+\mathrm{H}_{2}^{+}$from Rejoub et al [21] are also shown, to demonstrate that the discrepancy between the present data and Rejoub et al [21] is likely to be due to the omission of these small cations in the present results. 

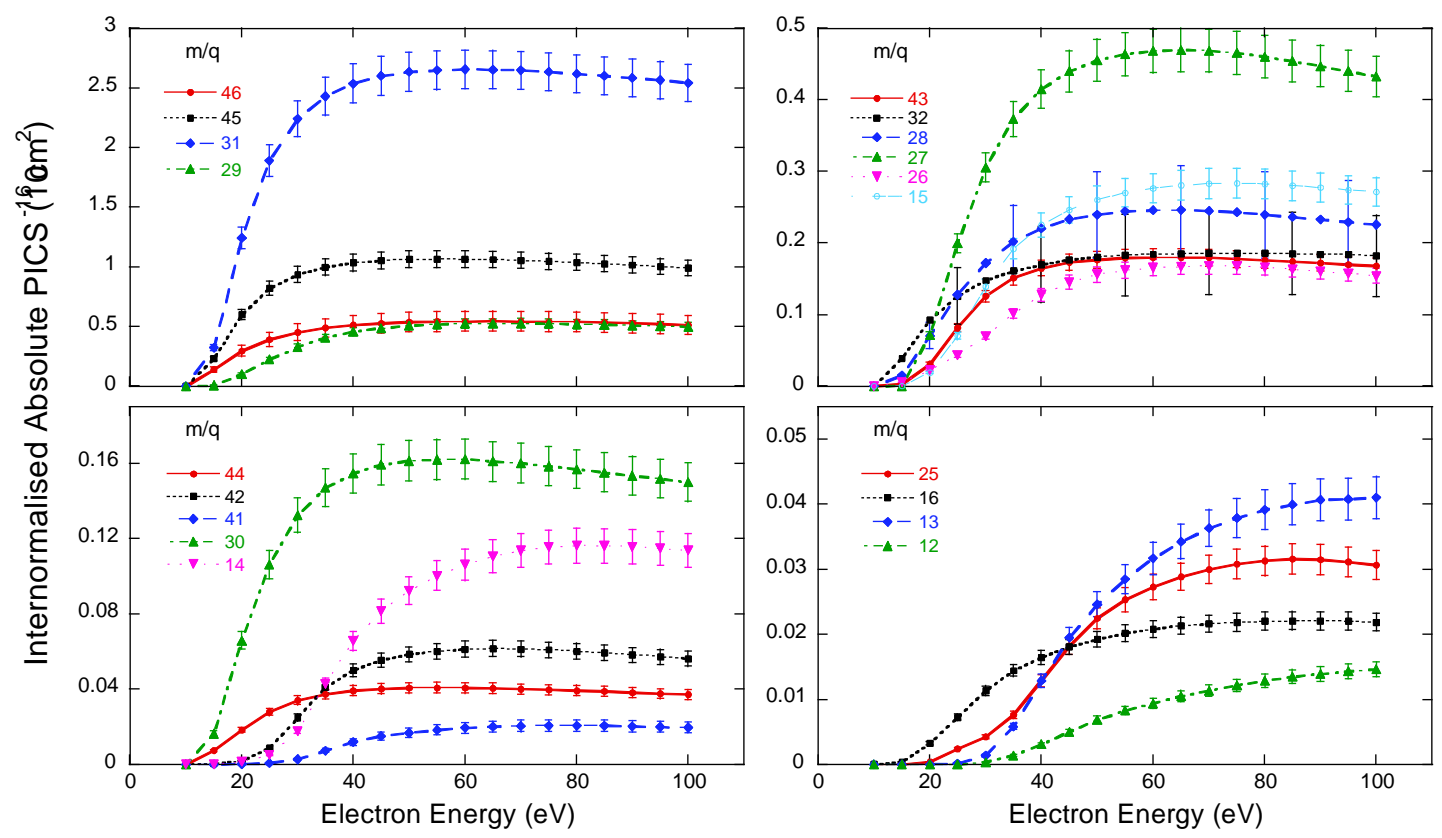

Figure 8: Absolute partial ionisation cross sections (PICS) for the 19 cations of ethanol measured in the present study. The errors are the quadrature sum of the uncertainty in the experimental measurements of the cross sections, the uncertainty of the relative contributions to the mass spectrum and the normalisation to the absolute data of Rejoub et al [21]. In the legends the cations are labelled in terms of their $\mathrm{m} / \mathrm{q}$, see text for their formulae. 


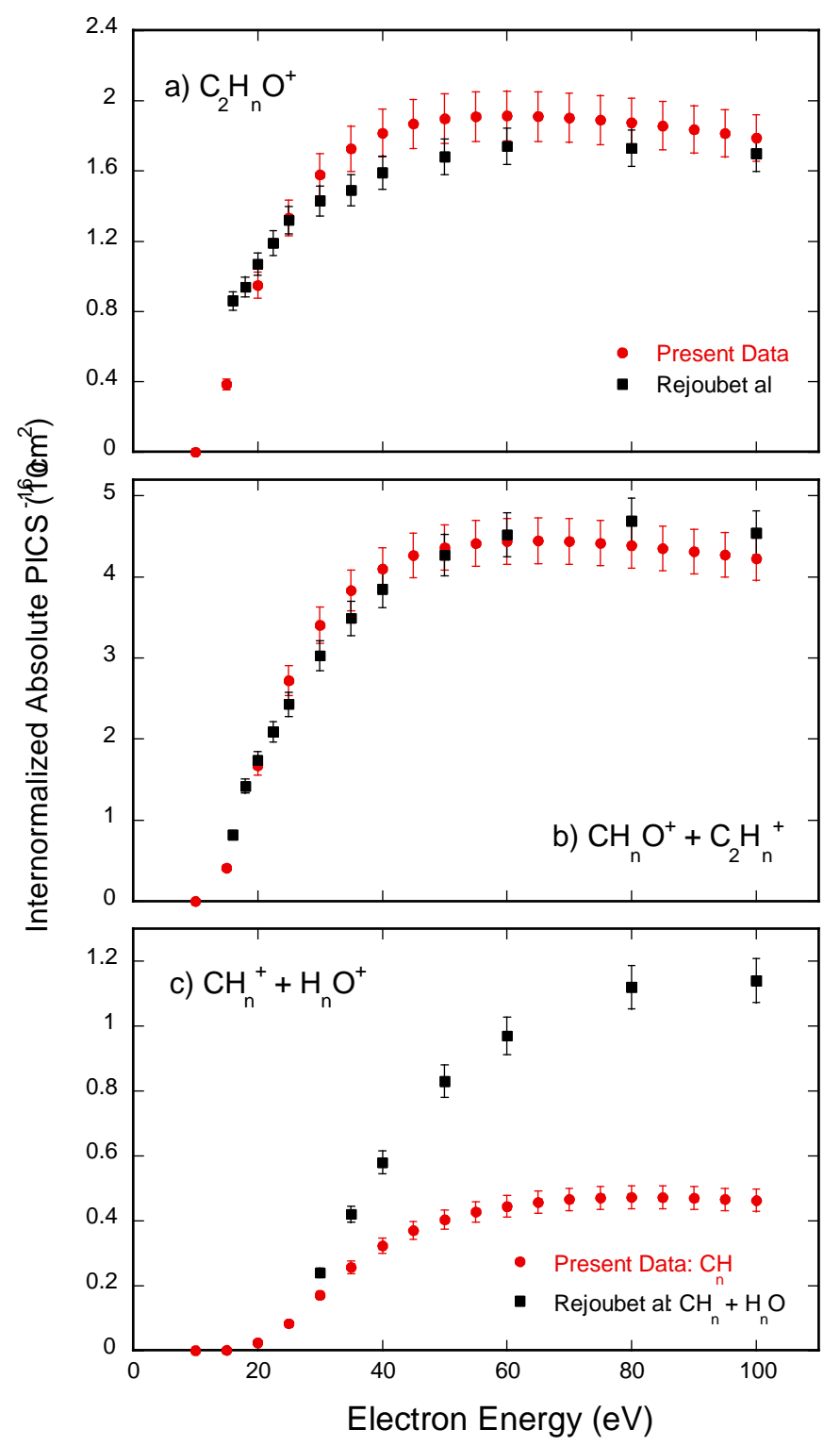

Figure 9: Absolute PICS of ethanol where the cations of similar masses have been summed together. In figure c) the present data has been summed over 12-15 amu, while the data of Rejoub et al [21] have been summed over $12-18 \mathrm{amu}$. 
Table 1: Relative abundances of the cations generated by electron impact of methanol using an electron energy of $70 \mathrm{eV}$, unless otherwise stated. The relative abundances are expressed with respect to the most abundant cation, i.e. $31 \mathrm{amu}$. The present data are determined from the average of several measurements and the error is the standard deviation on that average. Also shown is the background contribution to the measurements of methanol, given as a percentage. The data from this study is compared with the corresponding data from other sources.

\begin{tabular}{|c|c|c|c|c|c|c|c|c|c|}
\hline \multirow[t]{2}{*}{$\begin{array}{c}\text { Cation } \\
\text { Identity }\end{array}$} & \multirow[t]{2}{*}{$\mathbf{m} / \mathbf{z}$} & \multicolumn{2}{|c|}{ Present Data } & & \multirow[t]{2}{*}{ NIST [32] } & \multirow[t]{2}{*}{ Srivastava et al $[20]$} & \multirow[t]{2}{*}{ Douglas \& Price $^{\mathrm{a}}[26]$} & \multirow[t]{2}{*}{$\begin{array}{l}\text { Cummings \& } \\
\text { Bleakney [28] }\end{array}$} & \multirow[t]{2}{*}{ Szot et al $[43]$} \\
\hline & & Abundance & error & $\%$ Background & & & & & \\
\hline $\mathrm{H}^{+}$ & 1 & 5.10 & 0.65 & 14.6 & & & 30 & 3.0 & \\
\hline $\mathrm{H}_{2}^{+}$ & 2 & 2.14 & 0.45 & 7.4 & 0.3 & & 3.8 & 1.1 & \\
\hline $\mathrm{C}^{+}$ & 12 & 0.92 & 0.05 & 0.86 & 0.3 & 0.9 & 3.2 & 2.4 & \\
\hline $\mathrm{CH}^{+}$ & 13 & 1.65 & 0.11 & 0.32 & 0.6 & 0.2 & 6.7 & 3.0 & \\
\hline $\mathrm{CH}_{2}^{+}$ & 14 & 5.36 & 0.59 & 1.2 & 1.7 & 3.7 & 11.7 & 6.1 & 5 \\
\hline $\mathrm{CH}_{3}^{+}$ & 15 & 29.57 & 1.35 & 0.34 & 12.4 & 22.3 & 44 & 33.6 & 16 \\
\hline $\mathrm{H}_{2} \mathrm{O}^{+}$ & 18 & 1.48 & 2.92 & 86.4 & 0.7 & & 1.3 & & 32 \\
\hline $\mathrm{CO}^{+}$ & 28 & 11.86 & 7.55 & 10.8 & 4.6 & 7.1 & 7.6 & 46.3 & 10 \\
\hline $\mathrm{COH}^{+}$ & 29 & 50.0 & 1.15 & 1.09 & 44.6 & 56.9 & 76.5 & 76.1 & 58 \\
\hline $\mathrm{CH}_{2} \mathrm{O}^{+}$ & 30 & 9.44 & 0.43 & 0.40 & 6.5 & 7.8 & 9.3 & 9.0 & 12 \\
\hline $\mathrm{CH}_{2} \mathrm{OH}^{+}$ & 31 & 100.0 & 0.001 & 0.08 & 100 & 100 & 100 & 100 & 100 \\
\hline $\mathrm{CH}_{3} \mathrm{OH}^{+}$ & 32 & 76.35 & 1.56 & 0.33 & 74.4 & 71.8 & 64 & 56.8 & 76 \\
\hline${ }^{13} \mathrm{CH}_{3} \mathrm{OH}^{+}$ & 33 & 1.30 & 0.10 & 0.23 & 1.2 & & & & 3 \\
\hline
\end{tabular}

\footnotetext{
${ }^{\mathrm{a}}$ The data of Douglas et al. was taken with an impact energy of $75 \mathrm{eV}$
} 
Table 2: Relative abundances of the cations generated by electron impact of ethanol using an electron energy of $70 \mathrm{eV}$. The relative abundances are expressed with respect to the base peak, i.e. the most abundant cation at $31 \mathrm{amu}$. The present data are determined from the average of several measurements and the error is the standard deviation on that average. Also shown is the background contribution to the measurements of ethanol, given as a percentage. The molecular formulae are also given for the cations. In some cases the identity of the cation remains ambiguous. The data from this study is compared with the corresponding data from other sources.

\begin{tabular}{|c|c|c|c|c|c|c|}
\hline \multirow[b]{2}{*}{$\begin{array}{l}\text { Cation } \\
\text { formula }\end{array}$} & \multirow[b]{2}{*}{$\mathbf{m} / \mathbf{z}$} & \multicolumn{3}{|c|}{ Present Data } & \multirow[t]{2}{*}{ NIST [32] } & \multirow[t]{2}{*}{ Szot et al [44] } \\
\hline & & $\begin{array}{c}\text { Relative } \\
\text { Abundance }\end{array}$ & Error & \% Background & & \\
\hline $\mathrm{C}^{+}$ & 12 & 0.43 & 0.02 & 0.07 & 0.2 & \\
\hline $\mathrm{CH}^{+}$ & 13 & 1.37 & 0.07 & 0.14 & 1.39 & \\
\hline $\mathrm{CH}_{2}^{+}$ & 14 & 4.29 & 0.21 & 0.45 & 1.45 & \\
\hline $\mathrm{CH}_{3}^{+}$ & 15 & 10.69 & 0.45 & 0.22 & 6.6 & 2.77 \\
\hline $\mathrm{O}^{+}$or $\mathrm{CH}_{4}^{+}$ & 16 & 0.83 & 0.04 & 4.7 & - & \\
\hline $\mathrm{C}_{2}^{+}$ & 24 & 0.20 & 0.01 & 0 & 0.6 & \\
\hline $\mathrm{C}_{2} \mathrm{H}^{+}$ & 25 & 1.13 & 0.04 & 0.09 & 2.5 & \\
\hline $\mathrm{C}_{2} \mathrm{H}_{2}^{+}$ & 26 & 6.35 & 0.19 & 0.17 & 9.85 & 4.26 \\
\hline $\mathrm{C}_{2} \mathrm{H}_{3}^{+}$ & 27 & 17.71 & 0.43 & 0.21 & 22.4 & 19 \\
\hline $\mathrm{C}_{2} \mathrm{H}_{4}^{+}$or $\mathrm{CO}^{+}$ & 28 & 9.25 & 2.26 & 3.68 & 3.45 & 33 \\
\hline $\mathrm{COH}^{+}$or $\mathrm{C}_{2} \mathrm{H}_{5}^{+}$ & 29 & 19.98 & 0.82 & 0.4 & 29.9 & 30 \\
\hline $\mathrm{C} \mathrm{H}_{2} \mathrm{O}^{+}$or & & & & 0.12 & & 2.77 \\
\hline $\mathrm{C}_{2} \mathrm{H}_{6}^{+}$ & 30 & 6.05 & 0.15 & & 8.1 & \\
\hline $\mathrm{CH}_{2} \mathrm{OH}^{+}$ & 31 & 100 & 0.00 & 0.01 & 100 & 100 \\
\hline $\mathrm{CH}_{3} \mathrm{OH}^{+}$ & 32 & 7.02 & 2.14 & 1.38 & - & 2.56 \\
\hline $\mathrm{C}_{2} \mathrm{O}^{+}$ & 41 & 0.78 & 0.10 & 11.33 & 1.37 & \\
\hline $\mathrm{C}_{2} \mathrm{HO}^{+}$ & 42 & 2.32 & 0.07 & 0.96 & 4.75 & 6.18 \\
\hline $\mathrm{C}_{2} \mathrm{H}_{2} \mathrm{O}^{+}$ & 43 & 6.79 & 0.18 & 1.43 & 11.45 & 23 \\
\hline $\mathrm{C}_{2} \mathrm{H}_{3} \mathrm{O}^{+}$ & 44 & 1.51 & 0.05 & 1.87 & 0.75 & 5.54 \\
\hline $\mathrm{C}_{2} \mathrm{H}_{4} \mathrm{O}^{+}$ & 45 & 39.89 & 0.99 & 0.01 & 51.5 & 42 \\
\hline $\mathrm{C}_{2} \mathrm{H}_{5} \mathrm{O}^{+}$ & 46 & 20.56 & 2.89 & 0.01 & 21.6 & 4.9 \\
\hline${ }^{12} \mathrm{C}^{13} \mathrm{C} \mathrm{H}_{5} \mathrm{O}^{+}$ & 47 & 0.60 & 0.08 & & 0.73 & \\
\hline
\end{tabular}


Table 3: Appearance energies determined for ions of methanol (in $\mathrm{eV}$ ) by electron impact. The uncertainty in the present data is $\pm 0.5 \mathrm{eV}$.

\begin{tabular}{|c|c|c|c|c|c|c|}
\hline Cation & $\mathbf{m} / \mathbf{z}$ & Present Data & NIST [32] & $\begin{array}{c}\text { Srivastava et } \\
\text { al }[20]\end{array}$ & $\begin{array}{c}\text { Zavilopulo at } \\
\text { al [27] }\end{array}$ & $\begin{array}{c}\text { Cummings } \\
\text { \& Bleakney } \\
{[28]}\end{array}$ \\
\hline $\mathrm{CH}_{3} \mathrm{O}^{+} \mathrm{H}$ & 32 & 10.7 & 10.84 & & & 10.8 \\
\hline $\mathrm{CH}_{2} \mathrm{OH}^{+}$ & 31 & 11.1 & $\begin{array}{c}10.4^{\mathrm{a}}, 11.85^{\mathrm{b}}, 11.88^{\mathrm{c}}, 11.67^{\mathrm{d}, \mathrm{e}} 11.69^{\mathrm{f}} \\
\& 11.76^{\mathrm{g}}\end{array}$ & 13.12 & 11.50 & 11.8 \\
\hline $\mathrm{CH}_{2} \mathrm{O}^{+}$ & 30 & 10.6 & $10.9^{\mathrm{a}}$ & 13.12 & 10.52 & 12.4 \\
\hline $\mathrm{COH}^{+}$ & 29 & 11.4 & $14.0^{\mathrm{d}}$ & 14.6 & & 14.2 \\
\hline $\mathrm{CO}^{+}$ & 28 & & $13.7^{\mathrm{h}} \& 14.31^{\mathrm{i}}$ & 14.30 & 13.7 & \\
\hline $\mathrm{CH}_{3}^{+}$ & 15 & 14.0 & $13.5^{\mathrm{h}}$ & 17.56 & 13.5 & 14.0 \\
\hline $\mathrm{CH}_{2}^{+}$ & 14 & 14.1 & $15.3^{j}$ & 17.15 & & 15.4 \\
\hline $\mathrm{CH}^{+}$ & 13 & & $22.31^{\mathrm{k}}$ & 22.5 & & \\
\hline $\mathrm{C}^{+}$ & 12 & & & 20.96 & & \\
\hline
\end{tabular}

a. Mishchanchuk, B.G.; Pokrovskii, V.A.; Shabel'nikov, V.P.; Korol, E.N., Teor. Eksp. Khim., 1982, 18, 307.

b. Allam, S.H.; Migahed, M.D.; El-Khodary, A., Egypt. J. Phys., 1982, 13, 167.

c. Selim, E.T.M.; Helal, A.I., Indian J. Pure Appl. Phys., 1981, 19, 977.

d. Lifshitz, C.; Shapiro, M.; Sternberg, R., Israel J. Chem., 1969, 7, 391.

e. Bowen, R.D.; MacColl, A., Org. Mass Spectrom., 1984, 19, 379.

f. Lossing, F.P., , J. Am. Chem. Soc., 1977, 99, 7526.

g. Finney, C.D.; Harrison, A.G., Int. J. Mass Spectrom. Ion Phys., 1972, 9, 221.

h. Friedman, L.; Long, F.A.; Wolfsberg, M., J. Chem. Phys., 1957, 27, 613.

i. Friedland, S.S.; Strakna, R.E., J. Phys. Chem., 1956, 60, 815.

j. Friedman, L.; Long, F.A.; Wolfsberg, M., J. Chem. Phys., 1957, 27, 613.

k. Reed, R.I.; Snedden, W., J. Chem. Soc. Faraday Trans., 1956, 55, 876.

Table 4: Appearance energies in $\mathrm{eV}$ determined for ions of ethanol. The uncertainty in the present data is $\pm 0.5 \mathrm{eV}$.

\begin{tabular}{|c|c|c|c|c|c|}
\hline $\begin{array}{c}\text { Cation } \\
\text { Formula }\end{array}$ & $\mathbf{m} / \mathbf{z}$ & Present Data & NIST [32] & $\begin{array}{l}\text { Cummings \& } \\
\text { Bleakney [28] }\end{array}$ & $\begin{array}{c}\text { Zavilopulo et al } \\
{[27]}\end{array}$ \\
\hline $\mathrm{C}^{+}$ & 12 & & $22.9^{\mathrm{a}}$ & & 23.07 \\
\hline $\mathrm{CH}_{2}^{+}$ & 14 & & & 16.5 & \\
\hline $\mathrm{CH}_{3}^{+}$ & 15 & 14.0 & $14.70^{\mathrm{b}}$ & 15.5 & 14.62 \\
\hline $\begin{array}{l}\mathrm{O}^{+} \text {or } \\
\mathrm{CH}_{4}^{+}\end{array}$ & 16 & & $21.7^{\mathrm{a}}\left(\mathrm{O}^{+}\right)$ & & 21.56 \\
\hline $\mathrm{C}_{2} \mathrm{H}_{2}^{+}$ & 26 & 11.3 & & 14.1 & \\
\hline $\mathrm{C}_{2} \mathrm{H}_{3}^{+}$ & 27 & - & $14.7^{\mathrm{c}}$ & 14.5 & \\
\hline $\begin{array}{c}\mathrm{C}_{2} \mathrm{H}_{4}^{+} \text {or } \\
\mathrm{CO}^{+}\end{array}$ & 28 & 10.5 & $12.0^{\mathrm{d}}\left(\mathrm{C}_{2} \mathrm{H}_{4}\right)$ & $11.3\left(\mathrm{C}_{2} \mathrm{H}_{4}\right)$ & $12.55\left(\mathrm{C}_{2} \mathrm{H}_{4}\right)$ \\
\hline $\begin{array}{c}\mathrm{COH}^{+} \text {or } \\
\mathrm{C}_{2} \mathrm{H}_{5}^{+}\end{array}$ & 29 & 12.1 & & & 12.35 \\
\hline $\begin{array}{c}\mathrm{C} \mathrm{H}_{2} \mathrm{O}^{+} \text {or } \\
\mathrm{C}_{2} \mathrm{H}_{6}^{+}\end{array}$ & 30 & 10.3 & & 12.8 & 11.60 \\
\hline $\mathrm{CH}_{2} \mathrm{OH}^{+}$ & 31 & 10.7 & $11.25^{\mathrm{d}}, 11.40^{\mathrm{e}}, 11.30^{\mathrm{f}}$ & 11.3 & 11.18 \\
\hline $\mathrm{CH}_{3} \mathrm{OH}^{+}$ & 32 & 10.8 & & & \\
\hline $\mathrm{C}_{2} \mathrm{HO}^{+}$ & 42 & 9.6 & & & \\
\hline $\mathrm{C}_{2} \mathrm{H}_{2} \mathrm{O}^{+}$ & 43 & 9.8 & $14.5^{\mathrm{c}}$ & & \\
\hline $\mathrm{C}_{2} \mathrm{H}_{3} \mathrm{O}^{+}$ & 44 & 10.1 & $\sim 10.45^{\mathrm{g}}$ & 11.4 & \\
\hline $\mathrm{C}_{2} \mathrm{H}_{4} \mathrm{O}^{+}$ & 45 & 10.5 & $10.78^{\mathrm{d}}, 10.6^{\mathrm{h}}, 10.67^{\mathrm{f}}, 10.75^{\mathrm{i}}$ & 11.0 & \\
\hline $\mathrm{C}_{2} \mathrm{H}_{5} \mathrm{O}^{+}$ & 46 & 10.4 & 10.48 & 11.3 & \\
\hline
\end{tabular}

a. Stepanov, A.N.; Perov, A.A.; Kabanov, S.P.; Simonov, A.P., Russ. J. Phys. Chem., 1988, 22, 81

b. Haney, M.A.; Franklin, J.L., 1969, 65, 1794.

c. Friedman, L.; Long, F.A.; Wolfsberg, M., J. Chem. Phys., 1957, $27,613$.

d. Bowen, R.D.; MacColl, A., Org. Mass Spectrom., 1984, 19, 379.

e. Selim, E.T.M.; Helal, A.I., Indian J. Pure Appl. Phys., 1981, 19, 977.

f. Lossing, F.P., J. Am. Chem. Soc., 1977, 99, 7526.

g. Holmes, J.L.; Terlouw, J.K.; Lossing, F.P., J. Phys. Chem., 1976, 80, 2860.

h. Mishchanchuk, B.G.; Pokrovskii, V.A.; Shabel'nikov, V.P.; Korol, E.N., Teor. Eksp. Khim., 1982, 18, 307.

i. Solka, B.H.; Russell, M.E., J. Phys. Chem., 1974, 78, 1268. 
Table 5: Absolute partial ionisation cross sections $\left(\times 10^{-16} \mathrm{~cm}^{2}\right)$ measured for methanol. The standard deviations on the measured data are $<2 \%$, however, the overall uncertainty on the data given below must include also the uncertainty in the mass spectrum (given in table 1) and the error in normalising to the data of Rejoub et al [21] to establish the absolute scale (6\%). Therefore, the overall errors are 6.6, 6.1, 7.7, 6.5, 64, 7.5, 12.5, 9.1 and $8 \%$, respectively, for the PICS and $10 \%$ for the TICS.

\begin{tabular}{|c|c|c|c|c|c|c|c|c|c|c|}
\hline Electron Energy $(\mathrm{eV})$ & $\mathrm{CH}_{3} \mathrm{O}^{+} \mathrm{H}$ & $\mathrm{CH}_{2} \mathrm{O}^{+} \mathrm{H}$ & $\mathrm{CH}_{2} \mathrm{O}^{+}$ & $\mathrm{CO}^{+} \mathrm{H}$ & $\mathrm{CO}^{+}$ & $\mathrm{CH}_{3}{ }^{+}$ & $\mathrm{CH}_{2}^{+}$ & $\mathrm{CH}^{+}$ & $\mathbf{C}^{+}$ & Total \\
\hline 10 & 0.000 & 0.000 & 0.000 & 0.000 & 0.000 & 0.000 & 0.000 & 0.000 & 0.000 & 0.000 \\
\hline 15 & 0.341 & 0.210 & 0.020 & 0.005 & 0.001 & 0.001 & 0.000 & 0.000 & 0.000 & 0.578 \\
\hline 20 & 0.718 & 0.775 & 0.059 & 0.110 & 0.017 & 0.085 & 0.007 & 0.000 & 0.000 & 1.772 \\
\hline 25 & 0.940 & 1.163 & 0.094 & 0.297 & 0.041 & 0.201 & 0.021 & 0.000 & 0.000 & 2.757 \\
\hline 30 & 1.078 & 1.382 & 0.118 & 0.472 & 0.070 & 0.287 & 0.037 & 0.002 & 0.001 & 3.446 \\
\hline 35 & 1.164 & 1.508 & 0.132 & 0.590 & 0.104 & 0.344 & 0.052 & 0.007 & 0.003 & 3.904 \\
\hline 40 & 1.218 & 1.585 & 0.141 & 0.666 & 0.133 & 0.383 & 0.063 & 0.013 & 0.006 & 4.208 \\
\hline 45 & 1.253 & 1.634 & 0.147 & 0.720 & 0.153 & 0.412 & 0.071 & 0.018 & 0.009 & 4.417 \\
\hline 50 & 1.271 & 1.662 & 0.152 & 0.759 & 0.167 & 0.435 & 0.076 & 0.021 & 0.011 & 4.554 \\
\hline 55 & 1.277 & 1.672 & 0.154 & 0.787 & 0.177 & 0.452 & 0.080 & 0.023 & 0.012 & 4.635 \\
\hline 60 & 1.273 & 1.670 & 0.156 & 0.805 & 0.185 & 0.466 & 0.083 & 0.025 & 0.013 & 4.677 \\
\hline 65 & 1.266 & 1.659 & 0.156 & 0.817 & 0.191 & 0.477 & 0.086 & 0.026 & 0.014 & 4.692 \\
\hline 70 & 1.254 & 1.643 & 0.155 & 0.821 & 0.195 & 0.486 & 0.088 & 0.027 & 0.015 & 4.684 \\
\hline 75 & 1.242 & 1.624 & 0.154 & 0.822 & 0.196 & 0.492 & 0.089 & 0.028 & 0.016 & 4.663 \\
\hline 80 & 1.232 & 1.606 & 0.152 & 0.820 & 0.197 & 0.498 & 0.091 & 0.029 & 0.016 & 4.640 \\
\hline 85 & 1.229 & 1.595 & 0.151 & 0.817 & 0.198 & 0.504 & 0.092 & 0.029 & 0.017 & 4.632 \\
\hline 90 & 1.245 & 1.603 & 0.151 & 0.816 & 0.200 & 0.510 & 0.094 & 0.029 & 0.017 & 4.665 \\
\hline 95 & 1.245 & 1.595 & 0.150 & 0.810 & 0.199 & 0.513 & 0.095 & 0.030 & 0.018 & 4.654 \\
\hline 100 & 1.239 & 1.577 & 0.148 & 0.799 & 0.197 & 0.512 & 0.094 & 0.030 & 0.018 & 4.614 \\
\hline
\end{tabular}


Table 6: Absolute PICS and TICS for ethanol in units of $\mathrm{x}_{10}^{-16} \mathrm{~cm}^{2}$. The combined error (see text for more details) for each mass varies between 7-10\%, expect for $\mathrm{C}_{2} \mathrm{H}_{3}{ }^{+}$ (27 amu, 25\%), $\mathrm{C}_{2} \mathrm{HO}^{+}\left(41 \mathrm{amu}, 31 \%\right.$ ) and $\mathrm{CH}_{3} \mathrm{CHOH}^{+}(45 \mathrm{amu}, 15 \%$ ). The error on the TICS is $\sim 6 \%$.

\begin{tabular}{|c|c|c|c|c|c|c|c|c|c|c|c|}
\hline $\mathrm{E}(\mathrm{eV})$ & $\begin{array}{c}\mathbf{m} / \mathbf{z}=46 \\
\mathrm{CH}_{3} \mathrm{CH}_{2} \mathrm{O}^{+} \mathrm{H}\end{array}$ & $\begin{array}{c}\mathbf{m} / \mathbf{z}=\mathbf{4 5} \\
\mathrm{CH}_{3} \mathrm{CHO}^{+} \mathrm{H}\end{array}$ & $\begin{array}{c}\mathrm{m} / \mathrm{z}=44 \\
\mathrm{CH}_{3} \mathrm{CHO}^{+}\end{array}$ & $\begin{array}{c}\mathbf{m} / \mathbf{z}=43 \\
\mathrm{C}_{2} \mathrm{H}_{3} \mathrm{O}^{+}\end{array}$ & $\begin{array}{c}\mathrm{m} / \mathrm{z}=42 \\
\mathrm{C}_{2} \mathrm{H}_{2} \mathrm{O}^{+}\end{array}$ & $\begin{array}{c}\mathrm{m} / \mathrm{z}=41 \\
\mathrm{C}_{2} \mathrm{HO}^{+}\end{array}$ & $\begin{array}{l}\mathrm{m} / \mathrm{z}=32 \\
\mathrm{CH}_{3} \mathrm{O}^{+} \mathrm{H}\end{array}$ & $\begin{array}{l}\mathbf{m} / \mathbf{z}=31 \\
\mathrm{CH}_{2} \mathrm{O}^{+} \mathbf{H}\end{array}$ & $\begin{array}{c}\mathbf{m} / \mathbf{z}=30 \\
\mathrm{CH}_{2} \mathrm{O}^{+}\end{array}$ & $\begin{array}{c}\mathrm{m} / \mathrm{z}=29 \\
\mathrm{CO}^{+} \mathrm{H} \text { or } \\
\mathrm{C}_{2} \mathrm{H}_{5}^{+}\end{array}$ & $\begin{array}{c}\mathbf{m} / \mathbf{z}=\mathbf{2 8} \\
\mathrm{CO}^{+} \text {or } \mathrm{C}_{2} \mathrm{H}_{4}^{+}\end{array}$ \\
\hline 10 & 0.000 & 0.000 & 0.000 & 0.000 & 0.000 & 0.000 & 0.000 & 0.000 & 0.000 & 0.000 & 0.000 \\
\hline 15 & 0.141 & 0.233 & 0.007 & 0.003 & 0.001 & 0.000 & 0.000 & 0.324 & 0.016 & 0.010 & 0.015 \\
\hline 20 & 0.296 & 0.602 & 0.018 & 0.031 & 0.002 & 0.000 & 0.000 & 1.244 & 0.066 & 0.103 & 0.071 \\
\hline 25 & 0.393 & 0.821 & 0.028 & 0.082 & 0.009 & 0.001 & 0.000 & 1.891 & 0.106 & 0.224 & 0.128 \\
\hline 30 & 0.453 & 0.937 & 0.034 & 0.126 & 0.025 & 0.003 & 0.000 & 2.242 & 0.132 & 0.331 & 0.172 \\
\hline 35 & 0.491 & 0.999 & 0.037 & 0.151 & 0.041 & 0.007 & 0.000 & 2.431 & 0.147 & 0.408 & 0.202 \\
\hline 40 & 0.514 & 1.035 & 0.039 & 0.165 & 0.050 & 0.012 & 0.000 & 2.538 & 0.155 & 0.458 & 0.221 \\
\hline 45 & 0.529 & 1.055 & 0.040 & 0.173 & 0.055 & 0.015 & 0.000 & 2.600 & 0.159 & 0.489 & 0.233 \\
\hline 50 & 0.538 & 1.066 & 0.041 & 0.177 & 0.059 & 0.017 & 0.000 & 2.635 & 0.161 & 0.508 & 0.240 \\
\hline 55 & 0.543 & 1.068 & 0.041 & 0.179 & 0.060 & 0.018 & 0.000 & 2.649 & 0.162 & 0.519 & 0.245 \\
\hline 60 & 0.545 & 1.067 & 0.041 & 0.180 & 0.061 & 0.019 & 0.000 & 2.656 & 0.162 & 0.526 & 0.246 \\
\hline 65 & 0.546 & 1.062 & 0.041 & 0.180 & 0.062 & 0.020 & 0.000 & 2.655 & 0.161 & 0.528 & 0.246 \\
\hline 70 & 0.544 & 1.056 & 0.040 & 0.180 & 0.061 & 0.021 & 0.000 & 2.647 & 0.160 & 0.529 & 0.245 \\
\hline 75 & 0.543 & 1.048 & 0.040 & 0.178 & 0.061 & 0.021 & 0.000 & 2.635 & 0.158 & 0.526 & 0.243 \\
\hline 80 & 0.540 & 1.039 & 0.039 & 0.176 & 0.060 & 0.021 & 0.000 & 2.619 & 0.157 & 0.523 & 0.240 \\
\hline 85 & 0.535 & 1.028 & 0.039 & 0.175 & 0.059 & 0.021 & 0.000 & 2.600 & 0.155 & 0.519 & 0.237 \\
\hline 90 & 0.530 & 1.017 & 0.038 & 0.172 & 0.058 & 0.020 & 0.000 & 2.583 & 0.153 & 0.513 & 0.233 \\
\hline 95 & 0.523 & 1.006 & 0.038 & 0.170 & 0.057 & 0.020 & 0.000 & 2.565 & 0.152 & 0.507 & 0.230 \\
\hline 100 & 0.515 & 0.991 & 0.037 & 0.168 & 0.056 & 0.020 & 0.000 & 2.543 & 0.150 & 0.500 & 0.226 \\
\hline
\end{tabular}


Table 6 (cont...):

\begin{tabular}{|c|c|c|c|c|c|c|c|c|c|c|}
\hline E (eV) & $\begin{array}{c}\mathbf{m} / \mathbf{z}=\mathbf{2 7} \\
\mathrm{C}_{2} \mathbf{H}_{3}{ }^{+}\end{array}$ & $\begin{array}{c}\mathbf{m} / \mathbf{z}=26 \\
\mathrm{C}_{2} \mathrm{H}_{2}^{+}\end{array}$ & $\begin{array}{c}\mathbf{m} / \mathbf{z}=\mathbf{2 5} \\
\mathbf{C}_{2} \mathrm{H}^{+}\end{array}$ & $\begin{array}{c}\mathbf{m} / \mathbf{z}=\mathbf{2 4} \\
\mathrm{C}_{2}^{+}\end{array}$ & $\begin{array}{c}\mathbf{m} / \mathbf{z}=16 \\
\mathrm{O}_{2}^{+} \text {or } \mathrm{CH}_{4}^{+}\end{array}$ & $\begin{array}{c}\mathrm{m} / \mathbf{z}=15 \\
\mathrm{CH}_{3}{ }^{+}\end{array}$ & $\begin{array}{c}\mathrm{m} / \mathbf{z}=14 \\
\mathrm{CH}_{2}^{+}\end{array}$ & $\begin{array}{c}\mathbf{m} / \mathbf{z}=13 \\
\mathbf{C H}^{+}\end{array}$ & $\begin{array}{c}\mathrm{m} / \mathbf{z}=12 \\
C^{+}\end{array}$ & Total \\
\hline 10 & 0.000 & 0.000 & 0.000 & 0.000 & 0.000 & 0.000 & 0.000 & 0.000 & 0.000 & 0.000 \\
\hline 15 & 0.001 & 0.006 & 0.000 & 0.000 & 0.000 & 0.001 & 0.000 & 0.000 & 0.000 & 0.758 \\
\hline 20 & 0.072 & 0.023 & 0.000 & 0.000 & 0.003 & 0.019 & 0.001 & 0.000 & 0.000 & 2.554 \\
\hline 25 & 0.200 & 0.044 & 0.002 & 0.000 & 0.007 & 0.071 & 0.005 & 0.000 & 0.000 & 4.012 \\
\hline 30 & 0.306 & 0.070 & 0.004 & 0.001 & 0.011 & 0.140 & 0.018 & 0.001 & 0.000 & 5.007 \\
\hline 35 & 0.374 & 0.102 & 0.008 & 0.001 & 0.014 & 0.192 & 0.043 & 0.006 & 0.001 & 5.655 \\
\hline 40 & 0.415 & 0.128 & 0.013 & 0.002 & 0.016 & 0.225 & 0.066 & 0.013 & 0.003 & 6.068 \\
\hline 45 & 0.440 & 0.145 & 0.018 & 0.002 & 0.018 & 0.246 & 0.081 & 0.020 & 0.005 & 6.326 \\
\hline 50 & 0.455 & 0.156 & 0.022 & 0.003 & 0.019 & 0.260 & 0.092 & 0.025 & 0.007 & 6.483 \\
\hline 55 & 0.464 & 0.162 & 0.025 & 0.004 & 0.020 & 0.270 & 0.100 & 0.028 & 0.008 & 6.568 \\
\hline 60 & 0.468 & 0.166 & 0.027 & 0.004 & 0.021 & 0.276 & 0.106 & 0.032 & 0.009 & 6.614 \\
\hline 65 & 0.470 & 0.168 & 0.029 & 0.005 & 0.021 & 0.281 & 0.111 & 0.034 & 0.011 & 6.630 \\
\hline 70 & 0.469 & 0.168 & 0.030 & 0.005 & 0.022 & 0.283 & 0.114 & 0.036 & 0.011 & 6.621 \\
\hline 75 & 0.466 & 0.168 & 0.031 & 0.006 & 0.022 & 0.284 & 0.115 & 0.038 & 0.012 & 6.595 \\
\hline 80 & 0.460 & 0.166 & 0.031 & 0.006 & 0.022 & 0.282 & 0.116 & 0.039 & 0.013 & 6.550 \\
\hline 85 & 0.454 & 0.164 & 0.032 & 0.006 & 0.022 & 0.280 & 0.116 & 0.040 & 0.014 & 6.495 \\
\hline 90 & 0.447 & 0.161 & 0.032 & 0.007 & 0.022 & 0.278 & 0.116 & 0.041 & 0.014 & 6.436 \\
\hline 95 & 0.440 & 0.158 & 0.031 & 0.007 & 0.022 & 0.274 & 0.115 & 0.041 & 0.014 & 6.370 \\
\hline 100 & 0.433 & 0.154 & 0.031 & 0.007 & 0.022 & 0.271 & 0.114 & 0.041 & 0.015 & 6.294 \\
\hline
\end{tabular}

